Yves Wittwer, Robert Eichler*, Dominik Herrmann and Andreas Türler

\title{
The influence of physical parameters on the in- situ metal carbonyl complex formation studied with the Fast On-line Reaction Apparatus (FORA)
}

https://doi.org/10.1515/ract-2020-0035

Received April 8, 2020; accepted January 23, 2021; published online February 15, 2021

\begin{abstract}
The Fast On-line Reaction Apparatus (FORA) was used to investigate the influence of various reaction parameters onto the formation and transport of metal carbonyl complexes (MCCs) under single-atom chemistry conditions. FORA is based on a ${ }^{252} \mathrm{Cf}$-source producing short-lived Mo, Tc, Ru and Rh isotopes. Those are recoiling from the spontaneous fission source into a reaction chamber flushed with a gas-mixture containing CO. Upon contact with $\mathrm{CO}$, fission products form volatile MCCs which are further transported by the gas stream to the detection setup, consisting of a charcoal trap mounted in front of a HPGe $y$-detector. Depending on the reaction conditions, MCCs are formed and transported with different efficiencies. Using this setup, the impact of varying physical parameters like gas flow, gas pressure, kinetic energy of fission products upon entering the reaction chamber and temperature of the reaction chamber on the formation and transport yields of MCCs was investigated. Using a setup similar to FORA called Miss Piggy, various gas mixtures of CO with a selection of noble gases, as well as $\mathrm{N}_{2}$ and $\mathrm{H}_{2}$, were investigated with respect to their effect onto MCC formation and transport. Based on this measurements, optimized reaction conditions to maximize the synthesis and transport of MCCs are suggested. Explanations for the observed results supported by simulations are suggested as well.
\end{abstract}

Keywords: carbonyl complexes; single atom chemistry; transition metals.

\footnotetext{
*Corresponding author: Robert Eichler, Paul Scherrer Institute, Villigen, Switzerland, E-mail: robert.eichler@psi.ch

Yves Wittwer, Paul Scherrer Institute, Villigen, Switzerland; and University of Bern, Bern, Switzerland

Dominik Herrmann, Paul Scherrer Institute, Villigen, Switzerland Andreas Türler, University of Bern, Bern, Switzerland
}

\section{Introduction}

In 1890 , the synthesis and identification of $\mathrm{Ni}(\mathrm{CO})_{4}$ by Ludwig Mond and Co-workers marked the beginning of a new class of chemical compounds, the metal carbonyl complexes (MCCs) [1]. Nowadays, MCCs and their derivatives provide a large class of compounds with various applications including the usage as new pharmaceuticals and as reagents in organic chemistry [2-7]. A rather new application of MCCs focuses on the chemical investigations of transactinides (TAs). Transactinides are elements with a proton number $Z \geq 104$. Due to strong relativistic effects being expected to influence the electronic structures of elements in this heavy region of the periodic table, TAs might show unique and unexpected chemical properties [8-12]. However, chemical investigations of TAs are challenging. Since TAs were not found in nature up to today, they need to be produced in nuclear fusion reactions at a rate of a few atoms per day up to a few atoms per month depending on the investigated isotope. Additionally, their half-lives are generally low, being usually in the range of a few seconds $[8-10,13,14]$. Due to all these limitations, efficient and fast experimental setups are required to investigate TAs. Particularly, when using short-lived isotopes, studies are usually performed in the gas-phase. Since the refractory TAs $(Z=104-106)$ as well as noble metal TAs $(Z=107-111)$ are not volatile in their elemental state, this requires synthesizing a volatile TA compound first. In the past, volatile compounds synthesized from TAs included halides [15-20], oxyhalides [21-23], oxide hydroxides [24] and oxides [25] depending on the element $[8-10,13,26]$. Since MCCs are expected to be volatile enough for gas-phase studies, transforming TAs into MCCs might provide an efficient method to investigate those unique elements and to make them available in laboratories shielded from their production place using pure gasjets. Additionally, the metal atom in a MCC has a formal oxidation state of 0 , which is a new feature among all TA compounds investigated up to today. It is expected that $\mathrm{Sg}$, Bh, Hs and Mt form volatile MCCs, based on the behavior or their lighter homologous in the corresponding groups of the periodic table. Mt was not chemically investigated in 
the past at all [14, 27]. The synthesis of a volatile MCC from $\mathrm{Sg}, \mathrm{Sg}(\mathrm{CO})_{6}$ was recently accomplished by an international research group [28]. However, it became quickly apparent that the synthesis of MCCs under single-atom chemistry conditions goes along with low formation and transport yields. Interestingly, this was not only the case for heavy elements, but also for their lighter homologous. For example, $\mathrm{Mo}(\mathrm{CO})_{6}$ could only be produced with a yield of about $40 \%$. For $\mathrm{W}(\mathrm{CO})_{6}$ and $\mathrm{Sg}(\mathrm{CO})_{6}$, the overall yields were at maximum about 20 and 5\%, respectively [27]. These low yields represent a critical problem for the application of MCCs in transactinide research. Here, investigations are presented on the formation and transport of MCCs under similar single-atom chemistry conditions with the goal to clarify the impact of various physical and chemical reaction parameters and point out critical factors. The results are not only relevant in TA chemistry but potentially in other fields as well, for example the generation of new radioactive beams from refractory elements [29, 30]. To avoid the expensive and limited access to heavy ion accelerators, a model system called Fast On-line Reaction Apparatus (FORA) was constructed, allowing investigation of MCCs from Mo, Tc, Ru and Rh. The nuclides serve as model systems for elements of their corresponding groups 6 to 9 in the periodic table. The influence of gas flow, pressure, used gas mixture, temperature of the reaction chamber and kinetic energy of the atoms recoiling into the reaction chamber was investigated. To assist FORA, an older setup based on a similar principle, Miss Piggy [31], was used in some cases specified in the experimental section.

\section{Experimental}

\subsection{FORA}

The FORA-setup was already described in a previous study [32]. Briefly, the system is based on a ${ }^{252} \mathrm{Cf}$-source, which is located closely below a reaction chamber with two gas-inlets at the bottom and one gas-outlet at the top. An aluminum-wheel containing eight holes on its periphery and one closed position is mounted between the ${ }^{252} \mathrm{Cf}$-source and the reaction chamber. By turning this wheel, the reaction chamber can be opened towards the source. The holes in the aluminum-wheel can be occupied with degrader foils of various thicknesses, allowing to degrade the kinetic energy for fission products before entering the reaction chamber. The entire FORA-system is designed to be a closed gas-loop. After initially filling it with a process gas containing $\mathrm{CO}$, the system can be continuously operated. A set of exchangeable purification columns allows to control and maintain the purity of the used process gas. Pressure, gas flow and dew point of the process gas are continuously monitored. The gas flow is controlled using a Mass-FlowController (MFC). During operation, the ${ }^{252} \mathrm{Cf}$-source is opened towards the reaction chamber. Short-lived Mo, Tc, $\mathrm{Ru}$ and $\mathrm{Rh}$ isotopes produced in the spontaneous fission branch of ${ }^{252} \mathrm{Cf}$ are recoiling through a chosen hole of the aluminum-wheel and are entering the reaction chamber, where they thermalize and thus come into close contact with the gas flushing the reaction chamber. If the gas contains $\mathrm{CO}$, depending on the reaction conditions, volatile MCCs are formed in-situ and are transported out of the reaction chamber by the carrier gas flow. MCCs are transported through a $2 \mathrm{~m}$ long PFA-TEFLON ${ }^{\circledR}$ capillary until they reach a charcoal trap, where they are adsorbed. Using a HPGe $\gamma$-detector pointing at the charcoal trap, the decay of the shortlived isotopes is monitored. The formation and transport yield for each MCC compound is proportional to the spectroscopic signal of its corresponding metal isotope in the $\gamma$-spectrum. In all cases, it is assumed that fission products form MCCs if not mentioned otherwise. The isotopes ${ }^{104} \mathrm{Mo},{ }^{107} \mathrm{Tc},{ }^{110} \mathrm{Ru}$ and ${ }^{111} \mathrm{Rh}$ were chosen for investigation as described in [32]. The charcoal was purchased from Sigma-Aldrich, CO (99.997\%) was obtained from Carbagas. For measurements using FORA, given uncertainties were calculated according to a procedure described in detail elsewhere [32]. The scattering of data-points during operation under constant reaction conditions is indicative for the reproducibility of the measurement. Therefore, where not mentioned otherwise, the 2-sigma statistical error is given for measurements using FORA. Here, FORA was used to investigate the effects of gas flow, pressure, kinetic energy of fission products and temperature of the reaction chamber on the formation and transport of MCCs. In previous investigations using the FORA setup [32], it was found that the measured yields have a tendency to increase as a function of time, despite no apparent change of measurable reaction parameters, before reaching roughly constant values after about $12 \mathrm{~h}$. The effect is studied in [33] being related to the superposition of carrier-gas drying and the in-situ formation of macroscopic amounts of metal carbonyls from steel components of the loop. It was found to be only pronounced if FORA is completely evacuated and filled with fresh CO-gas. However, it is important to assure that such a systematic change in yield as a function of time does not interfere with the investigated reaction parameters. To avoid any significant contributions from such interferences, a number of safety measures was employed, which will be described in more detail in the chapter dealing with the investigated parameters. In summary, three safety precautions were employed:

- It was waited for at least $12 \mathrm{~h}$ after complete evacuation and refilling of the FORA setup with CO. This was done to minimize the influence of time-dependent effects. Additionally, continuous measurements were performed during this time period to assure a decent signal stability was achieved before starting any experiment.

- Measurements were performed in a randomized order. For example, in measurements where the pressure of the process gas was varied (compare with chapter 2.3), the investigated pressure values were not systematically increased or decreased, but randomly varied. If systematic, time dependent effects interfered with the performed measurements, this would results in a strong scattering of the obtained data. If, clear trends are observed instead, this means that the effects caused by the intended parameter changes had a stronger impact onto the investigated system than any unintended interference.

- Certain, selected measurements were repeated multiple times right after each other using identical reaction conditions. From the obtained scaterring of those values, the stability of the system and therefore the impact of time-dependent intereferences can be estimated. 
It is important to emphasize that the safety measures mentioned above were not employed to remove interferences, but to reduce their impact to a point where they are not significantly contributing to the observed trends, i.e., their impact is much smaller than the impact of the actually varied experimental parameter. The same is true for the so-called precursor effects which were investigated thoroughly for the selected fission product isotopes similar to [32]. No significant influence was observed, since quite distinct variations in trends have been observed for the genetically linked pairs of Mo/Tc, Tc/Ru and $\mathrm{Ru} / \mathrm{Rh}$ isotopes. However, at conditions, where the absolute yields are small, an influence of precursor effects cannot be excluded. A quantification attempt based on the $\gamma$-spectrometry results failed, due to the generally small activities at these conditions.

\subsection{Miss Piggy}

Next to FORA, an additional setup for investigating the formation of MCCs under single-atom chemistry conditions called Miss Piggy is located at the University of Bern. Miss Piggy was described in detail in $[31,34]$. The working principle is the same as for FORA with a ${ }^{252} \mathrm{Cf}-$ source producing short-lived isotopes forming MCCs, which are then transported to a charcoal trap where their decay is detected using $\gamma$-spectroscopy. Contrary to FORA, Miss Piggy is not operated as a gas loop. Gases can only be initially added and mixed using two MassFlow-Controllers (MFCs). The process gas flows through the reaction chamber, along a PFA-TEFLON $®$ capillary to the charcoal trap, connected to a pump over a needle valve. The schematic of the setup is depicted in Figure 1.

Gas flow and pressure in Miss Piggy are controlled using the initial MFCs and the needle valve located behind the charcoal trap. The pressure in the system is monitored at the gas-inlet. Miss Piggy was used to investigate the effects of different gas mixtures. The used gases CO (99.997\%), $\mathrm{CH}_{4}$ (99.95\%), $\mathrm{H}_{2}$ (99.999\%), $\mathrm{N}_{2}$ (99.999\%), $\mathrm{He}$ (99.999\%), Ne (99.99\%) and Ar (99.999\%) were all purchased from Carbagas.

\subsection{Pressure and gas flow}

Investigations on pressure and gas flow were performed very similarly. As previously noted, evacuating and refilling FORA with fresh process gas resulted in an initial continuous increase of MCC-yield lasting for about $12 \mathrm{~h}$, before reaching stable conditions [32]. This behavior is associated with a certain risk when evaluating pressure and gas flow dependencies continuously using FORA. Varying the gas flow and pressure requires to either add or remove process gas from the active gas-loop. Therefore, special care had to be taken that impurities are not added during those processes, which might cause interferences. Experiments with pressure variations were performed in
$100 \% \mathrm{CO}$ as well as in various gas mixtures: $75 \% \mathrm{CO}, 50 \% \mathrm{CO}$ and $25 \%$ $\mathrm{CO}$ with He. The gas flow was kept constant at $1000 \mathrm{ml} / \mathrm{min}$. In an additional measurement series, the pressure dependency in 100\% CO at two more gas flows, $750 \mathrm{ml} / \mathrm{min}$ and $500 \mathrm{ml} / \mathrm{min}$ respectively, was investigated as well. For $100 \%$ CO, pressures between 0.5 and 1 bar were investigated. For the other gas mixtures, the range between 0.65 and 1.15 bar was chosen. It was accounted for the fact that the actual gas flow is a function of pressure. The relationship is:

$$
Q_{\text {stand. }}=Q_{\text {real }} \times \frac{p_{\text {real }}}{p_{0}} \times \frac{T_{0}}{T_{\text {real }}}
$$

where $Q_{\text {stand }}$ is the standard gas flow as given by the MFC, $Q_{\text {real }}$ is the actual, real gas flow, $p_{\text {real }}$ and $T_{\text {real }}$ are pressure and temperature of the gas and $p_{0}$ and $T_{0}$ are standard values, $1 \mathrm{~atm}$ and $0^{\circ} \mathrm{C}$, respectively. In preliminary experiments, it was found that the pressures in front of the reaction chamber and in front of the charcoal trap were not much different. Therefore, a constant gas flow can be assumed between the reaction chamber and the charcoal trap. Thus, $p_{\text {real }}$ was set to the value indicated by the pressure sensor in front of the reaction chamber. $T_{\text {real }}$ was set to $25^{\circ} \mathrm{C}$. The MFC controlling the gas flow was then adjusted accordingly before removing or adding process gas in order to reach the desired pressure value. Like this, an interference from varying gas flows can be excluded during the pressure dependency measurements. The gas-correction factor for each MFC was adjusted to the investigated gas mixture according to the procedure given by MKS instruments [35]. The setup used to add and remove gas without interrupting the gas flow in FORA is depicted in Figure 2. Removal of process gas was performed by slowly removing process gas from the active loop between the charcoal trap and the membrane pump using a turbomolecular pump (Hi-Cube ${ }^{\mathrm{TM}}$, Pfeiffer $\mathrm{GmbH}$ ). A needle valve was used to control the gas flow into the pump. Care was taken to always maintain vacuum in the pump to avoid intake of air into the loop.

Two MFCs were used to mix and add fresh gas between the charcoal trap and the metal bellows pump at a gas flow rate of about $100 \mathrm{sml} / \mathrm{min}$. The low gas flow rate for adding process gas was chosen to avoid a pressure push to the charcoal trap. Pre-evacuation of the filling branch using a vacuum pump connected over a needle valve avoided the intake of air. A Sicapent ${ }^{\mathrm{TM}}$ column prevented the intake of moisture from the bottled gases. FORA was operated for at least $12 \mathrm{~h}$ after complete evacuation and refilling prior to starting experiments. Additionally, FORA was operated for $1.5 \mathrm{~h}$ before the start of each measurement after manipulating the process gas. This time was chosen to allow for purification of the process gas by the used purification columns. All pressure measurements were performed in a pseudorandomized order, namely $1 \mathrm{bar}, 0.75 \mathrm{bar}, 0.5 \mathrm{bar}, 0.65 \mathrm{bar}$ and at last 0.85 bar for $100 \%$ CO and 1 bar, 0.75 bar, 0.65 bar, 0.85 and 1.15 bar for mixtures to visualize possible unwanted systematic effects due to, e.g., intake of impurities. Therefore, gas was removed in the beginning to lower the system pressure and then added again at the end.

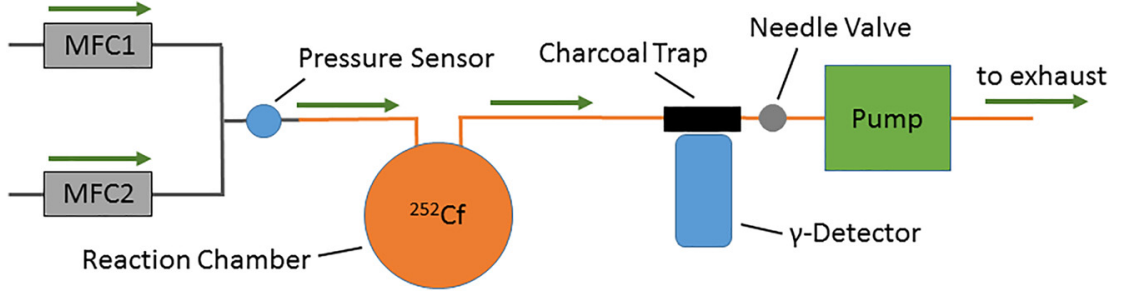

Figure 1: Schematic of the Miss Piggy based setup as used during the investigations presented here. The gray lines represent steel tubes, the orange ones PFA-TEFLON ${ }^{\circledR}$ tubes. A description is given in the text. MFC stands for Mass-Flow-Controller. 


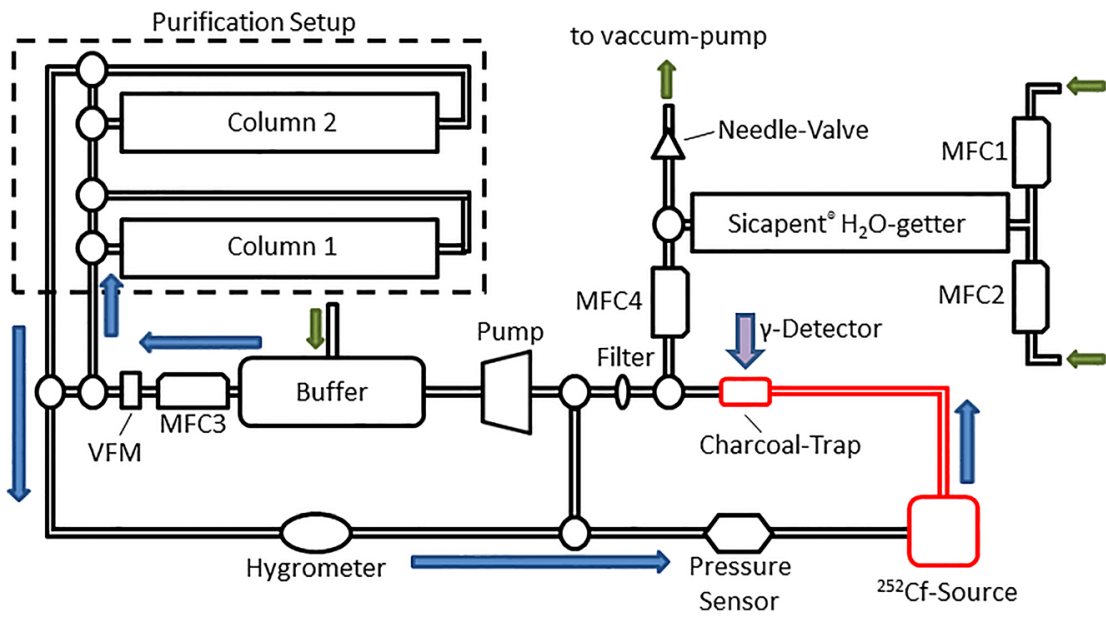

Figure 2: FORA setup as used during gas flow and pressure investigations.

The black parts are made from steel, the red ones from PFA-TEFLON $®$. The blue arrows mark the gas flow during normal operation, the green ones during addition/removal of process gas. The circles represent threeway valves. MFC stands for Mass-FlowController, VFM for Volume-Flow-Meter. MFC4 was turned to either add or remove gas at controlled gas flow rates. After complete evacuation, FORA was filled by adding gas directly into the buffer-volume (not shown here).
Measurements at 1.0 and 0.5 bar were repeated multiple times right after each other to reveal the reproducibility of the measurements. To vary the gas flow rate while keeping pressure constant, a very similar approach was used. Again, the necessary standard gas flow was calculated by Equation (1) to reach the desired actual gas flow while keeping pressure constant. The effect of gas flow on the overall yield was measured varying gas composition and pressure as follows: $100 \%$ $\mathrm{CO}$ at $1.0 \mathrm{bar}, 100 \% \mathrm{CO}$ at $0.5 \mathrm{bar}$ and a mixture of 50:50 CO:He at 1.0 bar. For the measurements at 1.0 bar, the gas flow was varied between $250 \mathrm{ml} / \mathrm{min}$ and $1250 \mathrm{ml} / \mathrm{min}$. For measurements at $0.5 \mathrm{bar}$, it was varied between $200 \mathrm{ml} / \mathrm{min}$ and $800 \mathrm{ml} / \mathrm{min}$. The same precautions as before were taken to avoid interferences. The order of the measurements was pseudo-randomized. A Sicapent ${ }^{\mathrm{TM}}$ column followed by a MicroTorr $602 \mathrm{~F}$ purification cartridge were used for process gas purification. Sicapent ${ }^{\mathrm{TM}}$ was used to remove moisture while the MicroTorr $602 \mathrm{~F}$ column is a professionally made purification column made specifically to purify $\mathrm{CO}$. It is certified to remove a large number of impurities, including $\mathrm{O}_{2}$ and $\mathrm{H}_{2} \mathrm{O}$ to volume concentrations $<1 \mathrm{ppb}$. CO, noble gases, $\mathrm{N}_{2}$ and $\mathrm{H}_{2}$ are not affected. All measurements had a duration of $3 \mathrm{~h}$. Sicapent ${ }^{\mathrm{TM}}$ was purchased from Merck, the MicroTorr $602 \mathrm{~F}$ cartridge was obtained from Pure Gas Products.

\subsection{Kinetic energy}

FORA allows to vary the kinetic energies of fission products entering the reaction chamber by making use of the aluminum-wheel mentioned above. The aluminum-wheel is depicted in Figure 3 in more detail. In order to adjust the kinetic energies of fission products recoiling from the ${ }^{252} \mathrm{Cf}$-source, the various holes are occupied with degrader foils of different thicknesses made from aluminum. By turning the wheel, which can be done without having to stop the FORA-system, different degrader foils are placed between source and chamber, serving as an additional barrier and thereby lowering the kinetic energy of any fission products entering the chamber.

In preparatory experiments, a large number of different foils between 1.5 and $9 \mu \mathrm{m}$ were tested. Since the transmission of fission products decreased quickly as a function of degrader thickness, only foils of 1.5, 2 and $3 \mu \mathrm{m}$ thickness were used or no degrader at all. Foils thinner than $1.5 \mu \mathrm{m}$ were not used due to their fragility and high tendency to be damaged during FORA operation. The aluminum-foils were purchased from Goodfellow. A number of reaction conditions were investigated in combination with various degraders. Two different purification setups were used. The first purification setup was the same as in previous accelerator based studies, consisting of a column filled with $\mathrm{MnO}$, to catch $\mathrm{O}_{2}$ and transform it into $\mathrm{CO}_{2}$, a column filled with TEPAN (Tetraethylenepentamine on Poly(methyl methacrylate)-adsorber, PMMA, support [36]), to adsorb $\mathrm{CO}_{2}$, and a Sicapent ${ }^{\mathrm{TM}}$ column to remove water impurities. The columns were mounted in this order. The second configuration was chosen to maximize the purity of the used process gas. A Sicapent ${ }^{\mathrm{TM}}$ followed by a MicroTorr $602 \mathrm{~F}$ column were used. Using MnO, TEPAN and Sicapent $^{\mathrm{TM}}$, the impact of kinetic energy was investigated in 50:50 gas mixtures of $\mathrm{CO}$ in $\mathrm{He}, \mathrm{N}_{2}$ and Ar. Pressure was set to 1 bar and gas flow to $1650 \mathrm{ml} / \mathrm{min}$, being the highest gas flow reliably achievable with FORA in this configuration. All measurements were performed in a random order to exclude time-dependent effects on the yields, as they were observed previously. A measurement time of $2 \mathrm{~h}$ was sufficient. It was waited for at least $12 \mathrm{~h}$ after setting up the system for equilibration of the gas purification before starting the measurements. All measurements were repeated three times. Using the second purification setup (MicroTorr 602F and Sicapent ${ }^{\mathrm{TM}}$ ), measurements in 100\% CO were performed at a gas flow rate of $1000 \mathrm{ml} / \mathrm{min}$ and a pressure of 1 bar. A few measurements were repeated to confirm consistency as well. Again, it was waited for at least $12 \mathrm{~h}$ after setting up the system before starting the measurements. Three hours long measurements were performed in this case. All yield data obtained for kinetic energy variations were corrected for the transmission rate of fission products through degrader foils with different thicknesses. A series of experiments was performed in advance to get the correction factors. Therefore, the reaction chamber shown in Figure 3 was removed and replaced with a stack of two $20 \mu \mathrm{m}$ thick aluminum-foils, which were placed directly on top of the investigated degrader foil and fixed with duct tape. The setup was placed in a steel-containment and evacuated before the wheel was turned, placing the investigated degrader foil and catcher foils above the ${ }^{252} \mathrm{Cf}$-source. Fission products were penetrating the degrader before entering the first $20 \mu \mathrm{m}$ aluminum-foil, which served as a catcher. The additional aluminum-foil above the first one served as a control to ensure all fission products were trapped by the first catcher foil. It was checked after each measurement for $\beta^{-}$activity using a contamination monitor (CoMo 170, Nuvia Instruments). A reference measurement was done using the same overall approach, but without a degrader foil between source and catcher foil. Fission products were collected for $63 \mathrm{~h}$ before the steel-containment 


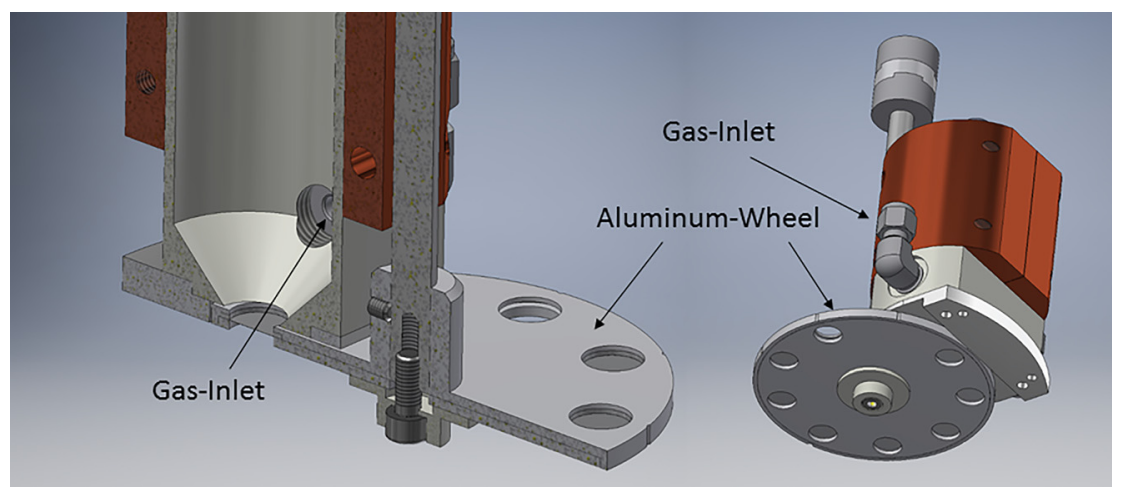

Figure 3: The aluminum-wheel with the reaction chamber mounted on top is depicted from two different angles. The left picture shows a cross section of the setup. The ${ }^{252} \mathrm{Cf}$-source is mounted directly under the chamber inlet below the wheel. The eight holes in the aluminum-wheel can be occupied with degrader foils of various thicknesses. One hole was always left open. The wheel includes a closed position. Also visible is one of the two gas-inlets of the chamber. The other one is located on the other side of the chamber.

was filled with air and the catcher foil was removed. The catcher foil was wrapped up, placed into a PFA-TEFLON $®$ tube and positioned subsequently in front of a $\gamma$-detector. After waiting for about $24 \mathrm{~h}$ to reduce the amount of interfering short-lived fission products decaying on the catcher foil, a $y$-spectrum was recorded for $24 \mathrm{~h}$. Care was taken to make sure that the procedure, including timing and measurement geometry, was the same for all catcher measurements.

Since timing and measurement geometry were equal for all catcher foil measurements, the determined peak areas in the $y$-spectra can be directly compared. By investigating a $\gamma$-peak corresponding to a rather long lived ${ }^{252} \mathrm{Cf}$ fission product as a function of degraderthickness, it is possible to determine the relative transmission of fission products with comparable atomic number through each degrader foil according to Equation (2).

$$
T(x)=\frac{A(x)}{A_{0}}
$$

$A(x)$ is the empirical $\gamma$-peak area of the chosen marker isotope measured corresponding to the catcher foil mounted on top of the degarder with thickness $x \mu \mathrm{m} . A_{0}$ is the empirical reference peak area for the same tracer isotope but collected without using a degrader foil. $T(x)$ is the fraction of fission products being collected by the catcher foil and therefore also entering the reaction chamber in a FORA experiment, with an $\mathrm{x} \mu \mathrm{m}$ thick degrader foil placed between ${ }^{252} \mathrm{Cf}$-source and catcher. The data measured in the actual FORA experiments are then corrected for the degrader foil transmission by dividing the obtained signal through the corresponding $\mathrm{T}(\mathrm{x})$-value (see Figure 4). ${ }^{103} \mathrm{Ru}$ $\left(t_{1 / 2}=39.26\right.$ days $)$ with an associated $y$-emission at $497 \mathrm{keV}$ was used as tracer isotope for this measurement. ${ }^{103} \mathrm{Ru}$ is produced with a cumulative fission yield of $5.45 \%$ by spontaneous fission of ${ }^{252} \mathrm{Cf}$. It is mostly implanted into the catcher foil as ${ }^{103} \mathrm{Zr},{ }^{103} \mathrm{Nb}$ and ${ }^{103} \mathrm{Mo}$ with independent fission yields of $0.84,3.06$ and $1.47 \%$ respectively [37]. Unfortunately, Mo, Tc and Rh do not have long-lives isotopes produced by spontaneous fission of ${ }^{252} \mathrm{Cf}$ suitable for similar determination studies of transmission rates. Their transmission rates as a function of different degrader-thicknesses were estimated to be the same as determined for ${ }^{103} \mathrm{Ru}$. This is considered appropriate since the atomic numbers of all investigated isotopes are close enough to ${ }^{103} \mathrm{Ru}$.

\subsection{Temperature}

To investigate the effect of temperature onto the formation of MCCs, an heating device was built to control elevated temperatures of the

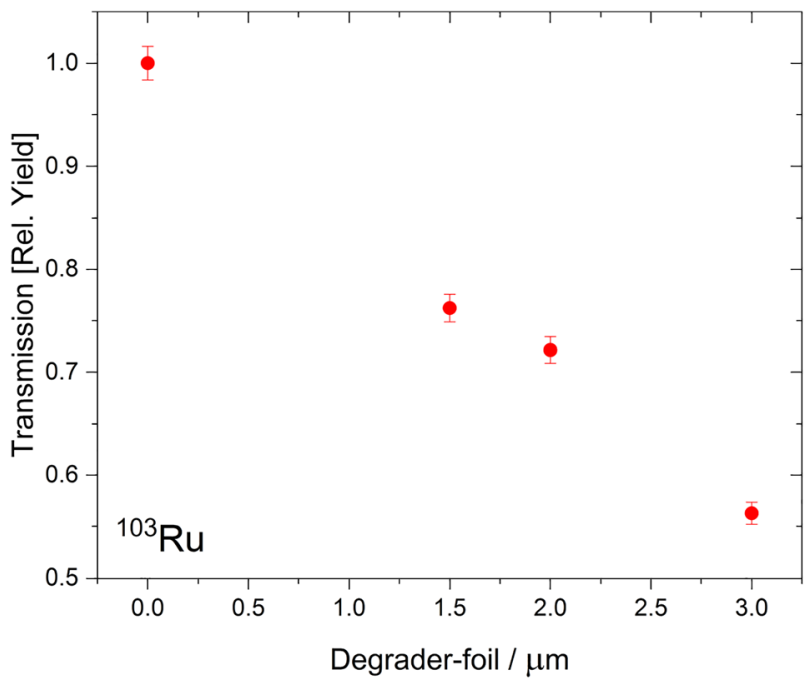

Figure 4: Experimentally measured transmission through degrader foils with different thicknesses in the FORA-setup.

A thickness of $0 \mu \mathrm{m}$ corresponds to not using any degrader foil at all. The error bars correspond to the statistical uncertainty of each measurement.

reaction chamber of FORA. The heater surrounding the chamber is depicted in Figure 5.

The heater was made from a copper-block with two heating elements. The heating elements (type: HS/VDE) were provided by Probag Wärmetechnik AG with a diameter of $6.5 \mathrm{~mm}$, a length of $40 \mathrm{~mm}$ and a heating power of 100 Watt. A thermocouple was used to monitor the temperature of the oven. Note that during regular operation the temperature of the copper-block was monitored, not the one of the actual gas flowing through the reaction chamber. Since the reaction chamber is made from PFA-TEFLON $®$, it was decided to limit the maximum investigated temperature to $150{ }^{\circ} \mathrm{C}$ to avoid any damage.

Figure 6 shows the temperature of the process gases used for temperature investigations as a function of the copper-heater temperature. The temperatures of the investigated gases and gas mixtures were measured in preparatory measurements by inserting a thermocouple into the volume of the reaction chamber before heating. The chamber was flushed with process gas at a pressure of 1.00 bar and 


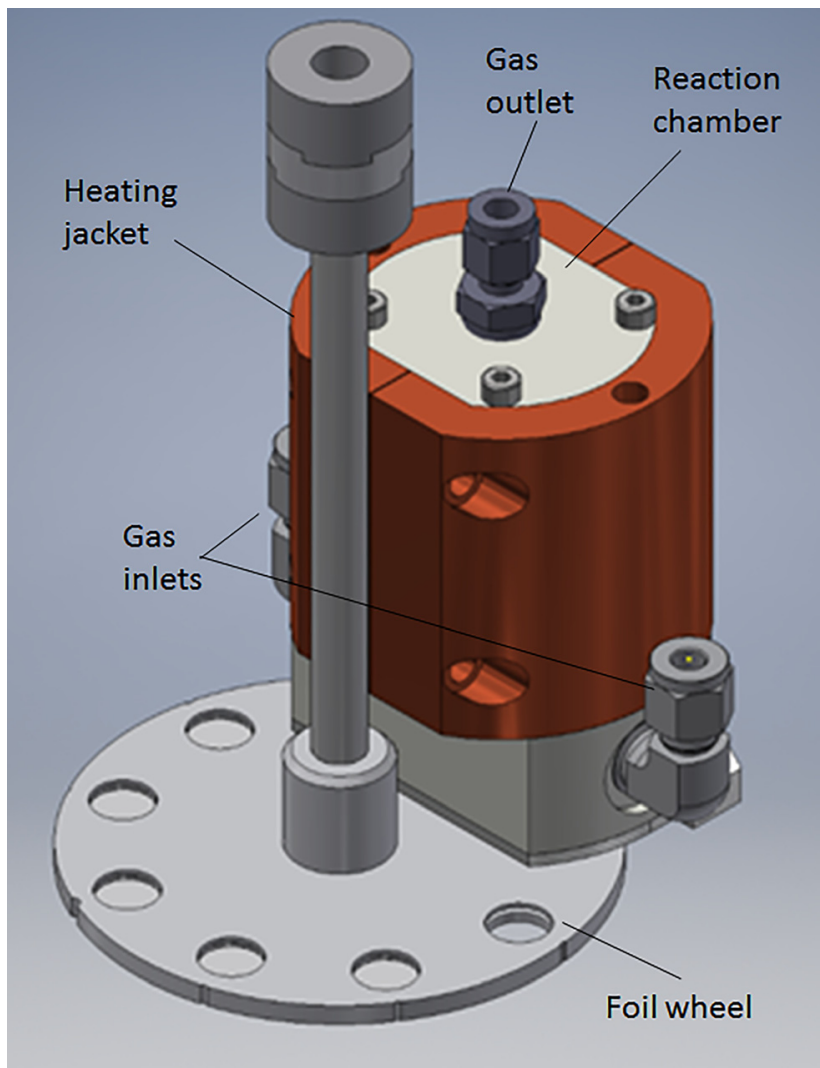

Figure 5: Top-view of the reaction chamber, emphasizing the copper heating jacket (brown mantle mounted around the chamber). The copper-block was heated using heating-elements that fitted into holes on top of the copper-mantle (one visible). The temperature was permanently monitored using a thermocouple mounted in an additional hole of the heating jacket.

$1000 \mathrm{ml} / \mathrm{min}$, resembling the conditions in the actual measurement. This thermocouple was removed for the subsequent FORA measurements to have the produced MCCs only in contact with PFA-TEFLON®. After evacuating and filling FORA with fresh process gas the gas loop was operated for at least $12 \mathrm{~h}$ before starting an experiment. The chamber was heated from RT to $150^{\circ} \mathrm{C}$ in steps of $50^{\circ} \mathrm{C}$, cooled down overnight and then heated again to 75 and $125^{\circ} \mathrm{C}$. Measurements were performed in 100\% CO and 50:50 CO:He at constantly 1 bar pressure and $1000 \mathrm{ml} / \mathrm{min}$ gas flow. A Sicapent ${ }^{\mathrm{TM}}$ and a MicroTorr $602 \mathrm{~F}$ purification cartridge were used permanently for gas purification. The measurement duration was set to $3 \mathrm{~h}$. Increasing the temperature of the process gas decreases its density which in turn decreases its stopping power. Using the ideal gas law, the data shown in Figure 6 and the SRIM software [38], the increase in ion range can be estimated to be about $18 \%$ for pure $\mathrm{CO}$ and $8 \%$ for a $50: 50$ gas mixture of $\mathrm{CO}: \mathrm{He}$ upon heating the reaction chamber from 25 to $150^{\circ} \mathrm{C}$. Especially for pure $\mathrm{CO}$, it cannot be excluded that this reduced the observed yield.

\subsection{Gas mixtures}

The synthesis and transport of MCCs in various gas-mixtures was investigated using Miss Piggy. Gases were mixed in a 1:1 ratio with one

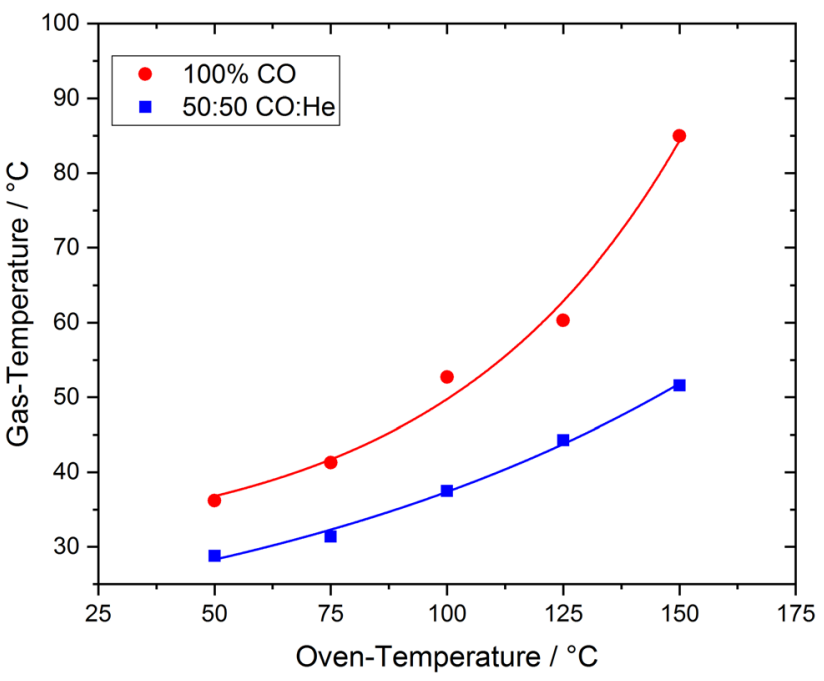

Figure 6: Temperature of the process gas passed through the reaction chamber as a function of the temperature of the heater. The red circles were measured using $100 \% \mathrm{CO}$, the blue squares were measured using 50:50 CO:He.

of the gases always being $\mathrm{CO}$ and the other one being varied. $\mathrm{He}, \mathrm{Ne}$, $\mathrm{Ar}, \mathrm{N}_{2}$ and $\mathrm{H}_{2}$ were investigated in this order. The entire measurement series was repeated three times. Prior to usage, Miss Piggy was flushed with $\mathrm{N}_{2}$ at $100 \mathrm{sml} / \mathrm{min}$ for two days. The pressure was kept constant at 1.2 bar. Slight over pressure was chosen to minimize potential air-intake. The total gas flow rate was set to be always equal to $600 \mathrm{sml} / \mathrm{min}$. The measurement time was set to $30 \mathrm{~min}$.

\subsection{Simulations}

The adsorption of MCCs during transport was simulated using Matlab R2019a. A Monte Carlo based method developed by I. Zvara was used [39]. The reaction chamber was represented by a $72 \mathrm{~mm}$ long tube with a diameter of $40 \mathrm{~mm}$ followed by a $2 \mathrm{~m}$ long tube with a diameter of $2 \mathrm{~mm}$, both made from PFA-TEFLON®. The chamber is illustrated in Figure 7. In the code, this was achieved by changing the inner diameter of the column from 40 to $2 \mathrm{~mm}$ as soon that a particle traveled further than $72 \mathrm{~mm}$. The corresponding adsorption enthalpies on PFA-TEFLON® ${ }^{\circledR}$ were taken from [40-42]. 10,000 particles were simulated for each investigated experimental condition. Simulations targeted at determining the number of surface interactions of a molecule during transport were performed using the same simulation. It was counted how often a molecule collides with a surface on its way to the charcoal trap. The value depicted in Figure 12 is the mean value of 10,000 simulated molecule trajectories for each investigated condition. Only the capillary connecting the reaction chamber and the charcoal trap was considered for this simulation. Simulations concerning the range of fission products in the reaction chamber were performed using a combination of SRIM2013 [38] and Matlab R2019a. The general method will be briefly summarized in here. Detailed descriptions for all simulations and calculations are given in the supporting information. In a first step, it is considered that fission products must be emitted from the fission source with a certain initial trajectory in order to cross the aluminum-wheel between ${ }^{252} \mathrm{Cf}$ source and reaction chamber, serving as a collimator. Using a Monte Carlo 


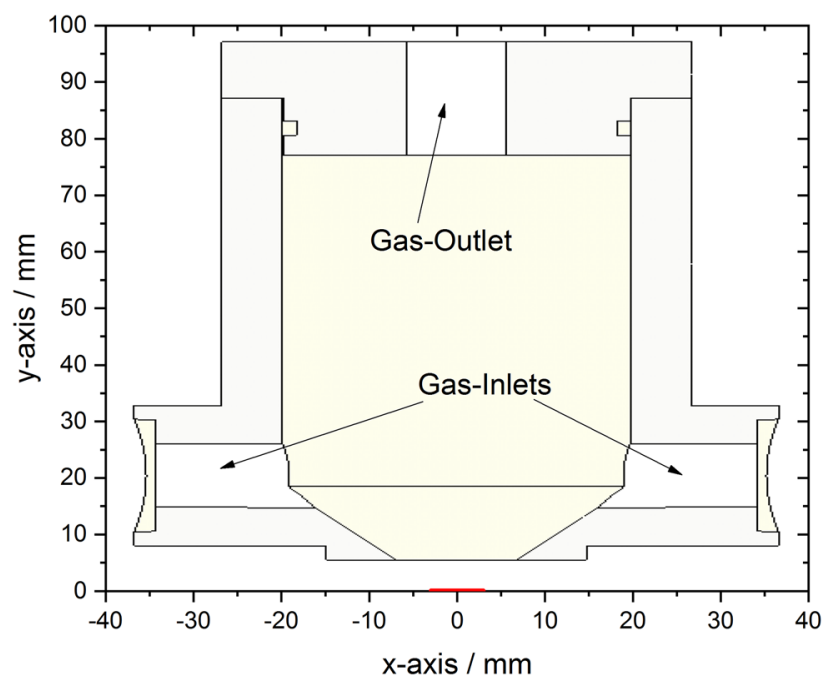

Figure 7: The schematic of the reaction chamber in the FORA setup. The ${ }^{252} \mathrm{Cf}$ fission source is located below the chamber (indicated by the red bar).

based approach, suitable initial trajectories were determined for 10,000 recoiling atoms. In a second step, those initial trajectories are used as input for the SRIM-software [38], which evaluates the range and complete trajectories of fission products in a set matrix. The SRIM-software calculates the position of each of the 10,000 particles after being thermalized. These positions were used for further evaluation. The matrices were adapted to each experiment. They included the used process gas as well as degrader foils.

Simulations were performed for ${ }^{104} \mathrm{Mo}$ with an initial energy of $103 \mathrm{MeV}$ [43]. They should be representative for ${ }^{107} \mathrm{Tc},{ }^{110} \mathrm{Ru}$ and ${ }^{111} \mathrm{Rh}$ as well due to similar atomic numbers. A correction factor determined from [44] was used to account for the underestimation of stopping power by SRIM in the gas phase.

\subsection{Absolute yields}

As it was described in more detail in [32], converting the obtained data into absolute chemical yields for the synthesis of each investigated species is possible in principle, but results in large uncertainties. These uncertainties are not caused by the quality of the performed measurements, but by the literature values required for calculation, especially $\gamma$-branching ratios and fission yields, as well as the efficiency calibration of the gamma detector. Due to this reason, the data presented here are not converted to absolute yields but instead normalized as described in the caption of each figure for the error bars to reflect the precision of the actual measurement and allow for a proper representation of the investigated trends. To give a rough estimation concerning the efficiency of the chemical reactions observed in this study as well as to give a rough idea about the differences in yields for the different investigated species, the absolute chemical yields for the highest and lowest activities measured during the studies presented here are shown for each species in Table 1 . The absolute chemical yields were calculated using a method based on determining the activity of the ${ }^{252} \mathrm{Cf}$ source used within FORA by using catcher foils. The method is described in [33]. Note again that the large uncertainties given are not caused by the quality of the measurements
Table 1: Highest and lowest absolute chemical yields for each MCC-species investigated during this study.

\begin{tabular}{lrr}
\hline Chemical Speces & Lowest chemical yield & Highest chemical yield \\
\hline${ }^{104} \mathrm{Mo}(\mathrm{CO})_{6}$ & $5 \pm 1$ & $57 \pm 15$ \\
${ }^{107} \mathrm{Tc}(\mathrm{CO})_{n}$ & 0 & $18 \pm 4$ \\
${ }^{110} \mathrm{Ru}(\mathrm{CO})_{5}$ & $2 \pm 1$ & $35 \pm 17$ \\
${ }^{111} \mathrm{Rh}(\mathrm{CO})_{m}$ & 0 & $25 \pm 4$ \\
\hline
\end{tabular}

presented here, but by the reference values required for calculation. In case of $\mathrm{Tc}(\mathrm{CO})_{n}$ and $\mathrm{Rh}(\mathrm{CO})_{m}$, the lowest obtained yields correspond to non-observation above background signal in the associated gamma spectra.

\section{Results and discussion}

\subsection{Gas flow}

The dependency of the overall MCC-yield on the gas flow was investigated for two different gas mixtures and two pressures. Results are depicted in Figures 8-10.

According to the results presented here, high gas flows are desirable in any case, having a rather large impact on the overall yield for MCCs. On a first glance, this is intuitively understandable since high gas flows result in lower transport times and therefore higher yields, especially for elements with short half-lives. However, the black points in Figures 8-10 connected by dotted lines represent the expected yield assuming the decay of the isotopes under consideration during their transport to be relevant. It is based on a simple volume-flow model, which is further described in the supporting information. The prediction generally overestimates the yields. Overestimation is especially severe for Mo. ${ }^{104} \mathrm{Mo}$, has the longest half-life of all investigated isotopes and should therefore be the least sensitive towards gas flow alterations. Experimentally, it is observed that Mo is about equally sensitive towards gas flow variations as the other elements, indicating that the observed behavior cannot be caused by pure transport time effects. Aside from pure transport based effects, adsorption retention might cause the observed yield drop too.

In Figure 11, data obtained in $100 \% \mathrm{CO}$ at 1 bar and a gas flow of $1000 \mathrm{ml} / \mathrm{min}$ are compared with simulations including the effects of adsorption during transport from the reaction chamber to the charcoal trap. Introducing the effect of adsorption does not significantly impact the predicted yields in comparison with the model only accounting for overall transport. The effect is not explaining the observed difference between experiment and prediction. An alternative explanation would be the formation of side 


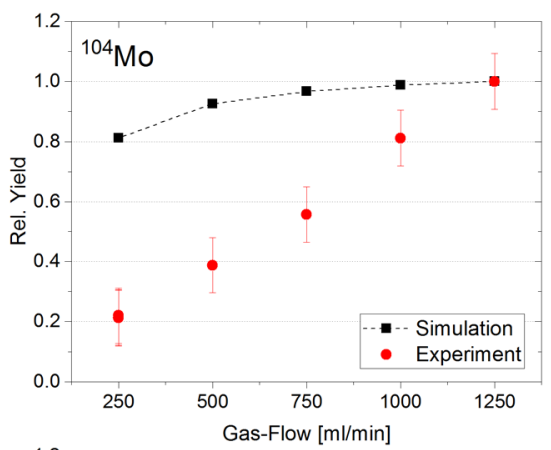

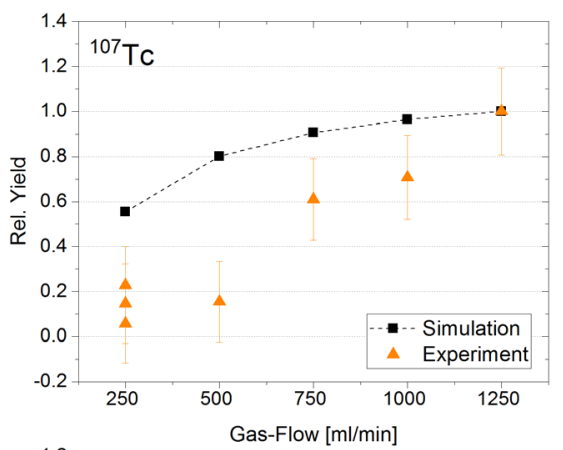

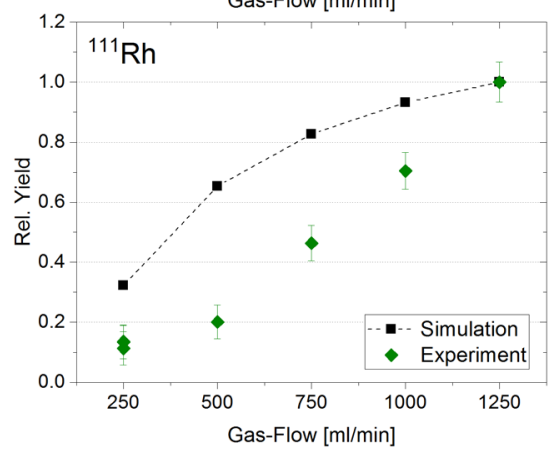

Figure 8: Effect of changing gas flows onto formation and transport of MCCs.

The experimental data are shown as colored symbols. 50:50 CO:He at 1 bar was used. The actual gas flow calculated by Equation (1) is depicted. The black squares connected by black, dotted lines correspond to expectation values based on transport time and thus decay loss assuming a laminar flow profile. The data are normalized to the highest measured yield.
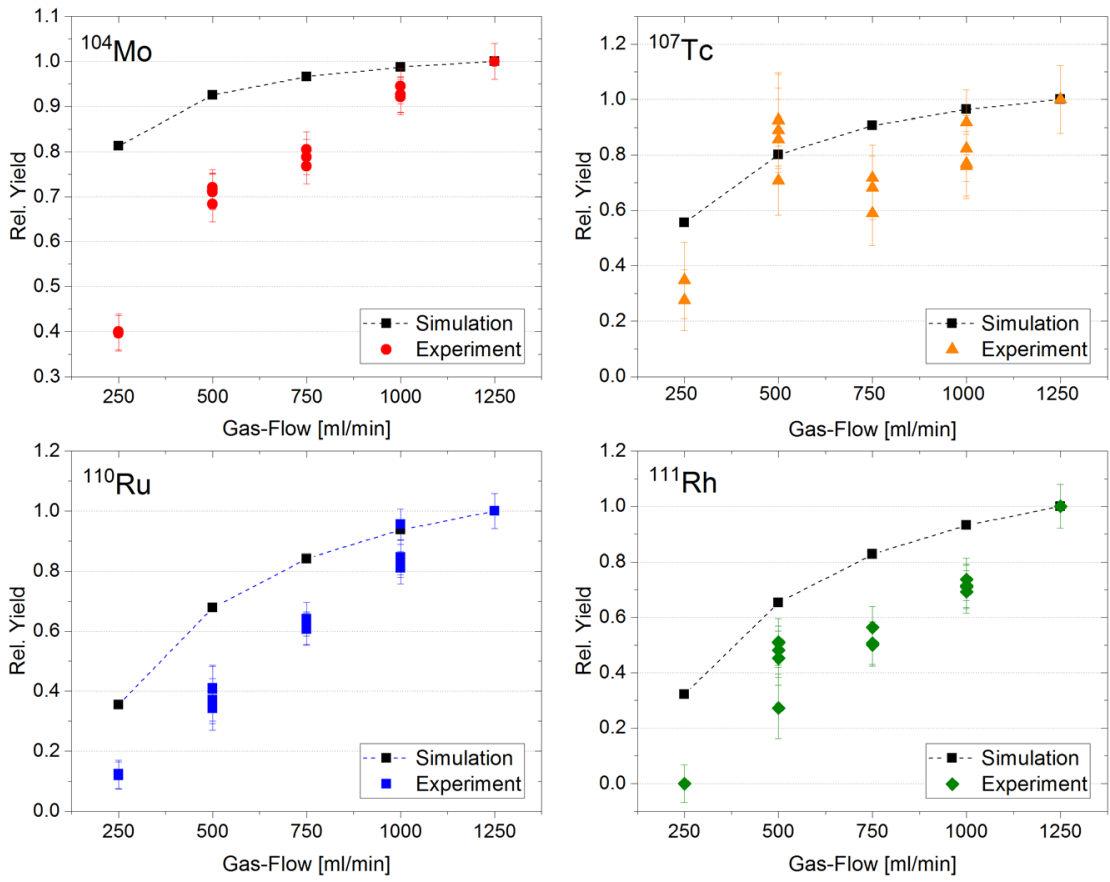

Figure 9: Effect of changing gas flows onto formation and transport of MCCs.

The experimental data are shown as colored symbols. $100 \%$ CO at 1 bar was used. The data are normalized to the highest signal. The actual gas flow calculated by Equation (1) is depicted. The black squares connected by black, dotted lines correspond to expectation values based on transport time and thus decay loss assuming a laminar flow profile. The data are normalized to the highest measured yield.

products. If side reactions with $\mathrm{O}_{2}$ or $\mathrm{H}_{2} \mathrm{O}$ are assumed to take place during transport, a shorter transport time might reduce the degree of non-volatile side product formation due to a more limited reaction time available. The formation of radioactive MCCs in FORA upon addition of various impurities was studied in the past [32]. An effect of $\mathrm{O}_{2}$ is very unlikely for Mo, Tc and $\mathrm{Ru}$, since a reduction of yield for their associated volatile compounds was only observed at high $\mathrm{O}_{2}$-concentrations. An effect of $\mathrm{H}_{2} \mathrm{O}$ is more probable. Nevertheless, studies concerning the mechanism behind the yield-reducing effect of $\mathrm{O}_{2}$ and $\mathrm{H}_{2} \mathrm{O}$ were also performed, during which it was shown that impurities mostly affect the formation of MCCs, while the transport is less affected. However, the coverage of PFA-TEFLON® with adsorbed $\mathrm{H}_{2} \mathrm{O}$ is still expected to have a strong impact on the transport yield of MCCs, as surface reactions of MCCs 

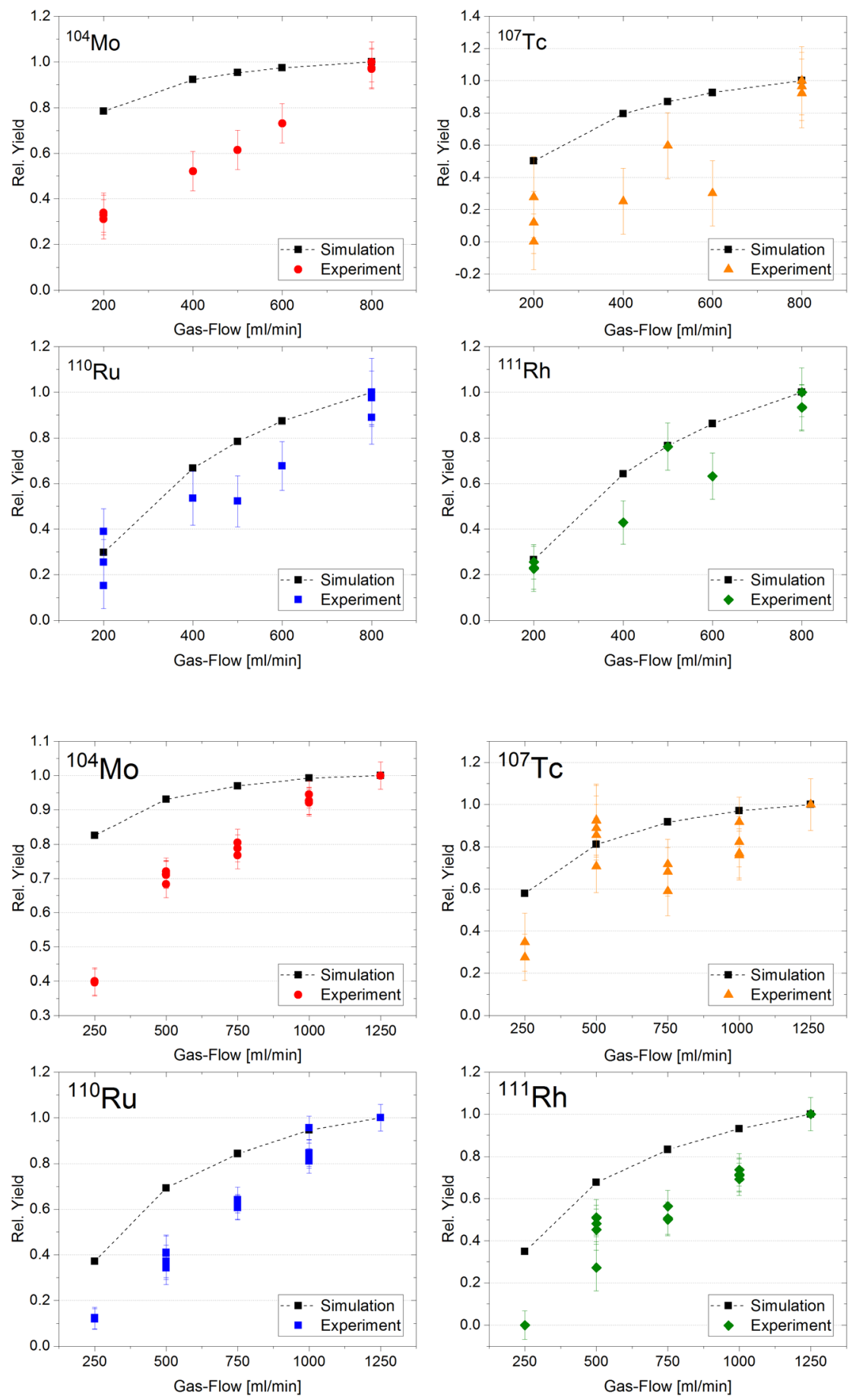

Figure 10: Effect of changing gas flows onto formation and transport of MCCs.

The experimental data are shown as colored symbols. $100 \%$ CO at 0.5 bar was used. The data are normalized to the highest signal. The actual gas flow calculated by Equation (1) is depicted. The black squares connected by black, dotted lines correspond to expectation values based on transport time and thus decay loss assuming a laminar flow profile. The data are normalized to the highest measured yield.

Figure 11: The data from Figure 9 compared with simulations including the effects of adsorption (see text for details).

The colored symbols correspond to the experimental data measured in $100 \% \mathrm{CO}$ at 1 bar. The black squares connected by dotted black lines correspond to expectation values based on transport time and thus decay loses including the effect of adsorption on PFA-TEFLON®. with moisture might cause significant losses. It is assumed that MCCs are in an equilibrium with partially decomposed products. For example:

$$
\mathrm{Mo}(\mathrm{CO})_{6} \rightleftharpoons \mathrm{Mo}(\mathrm{CO})_{5}+\mathrm{CO}
$$

If such a decomposition reaction happens in the adsorbed state of the carbonyl in close proximity to $\mathrm{H}_{2} \mathrm{O}$ adsorbed on PFA-TEFLON®, it is expected to cause side reactions forming non-volatile products upon adsorption. As an increased gas flow reduces possible interactions between MCCs and the walls with adsorbed $\mathrm{H}_{2} \mathrm{O}$, this reveals a favorable effect on the overall yield. Additional indication arises from the results during investigations of the reaction temperature (see Section 2.5). 

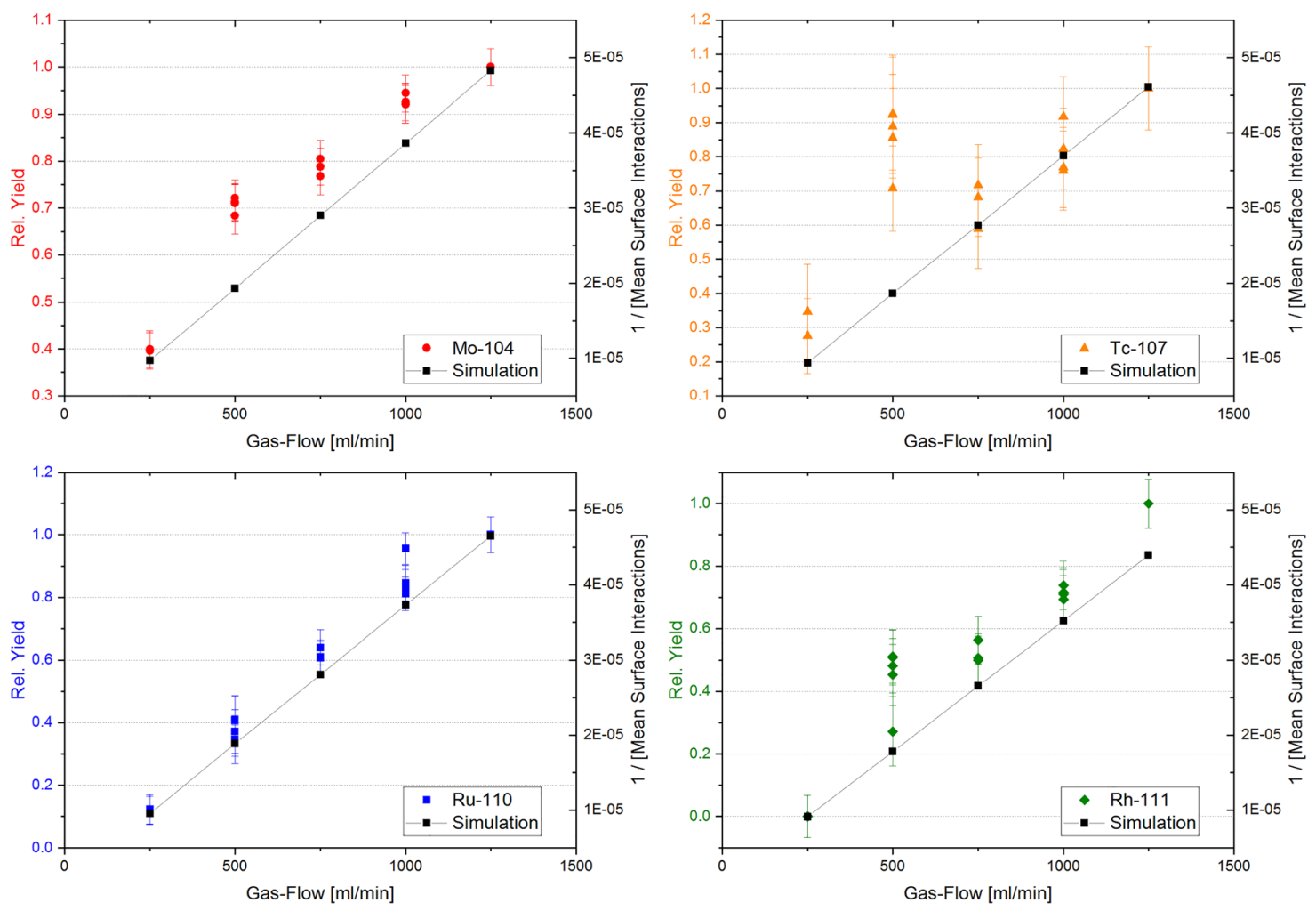

Figure 12: The data from Figure 9 compared with simulations counting the number of surface interactions of a carbonyl complex while being transported from the reaction chamber to the charcoal trap.

Shown is the average number of surface interactions simulated for 10,000 particles at each gas flow. To allow for comparison with the experimental data, the inverse number of average interactions is shown. The colored, left $y$-axis represents the experimental data, the black, right $y$-axis the simulations.

In order to gain additional evidence for this assumption, it was simulated how often a carbonyl complex encounters a surface on its way from the reaction chamber to the charcoal trap as a function of the applied gas flow (compare with chapter 2.7). The results are shown in Figure 12. The obtained simulations qualitatively reproduce the experimentally obtained linear trends very well, which provides support to the assumption that surface collisions as a function of the gas flow correlate with the experimentally observed trends, probably due to side reactions with adsorbed $\mathrm{H}_{2} \mathrm{O}$.

\subsection{Pressure}

The resulting yields for the four investigated tracer isotopes forming MCCs obtained for pressure variations in different gas mixtures are depicted in Figures 13-16. Pressure investigations for different gas flows are depicted in Figures 17 and 18.
For Mo and $\mathrm{Rh}$, an increase in yield upon increasing pressure is observed independent of other reaction conditions. For Mo, the effects correspond to an increase between 10 and $30 \%$ with higher pressure in the investigated range. For $\mathrm{Rh}$, the effect is stronger, amounting to about $20-50 \%$. For Tc and Ru, the pressure-dependency appears to be less pronounced. The observed increase in yield upon increasing the system pressure was already observed in previous studies by Usoltsev [34]. The data shown here confirm this. The effect is expected to be related to an increased collision frequency with CO-molecules at high pressure and increased diffusion times for both, the incomplete MCC products to the walls and the reactive trace contaminants to the incomplete MCC products. It is unexpected that the effect of pressure appears to be less pronounced for Tc and Ru in comparison with Mo and $\mathrm{Rh}$. The effects can neither be assigned to increased impurity concentrations upon pressure increase nor to transport effects. ${ }^{111} \mathrm{Rh}$ has the shortest half-life and is expected to be the most sensitive element towards impurities in the 

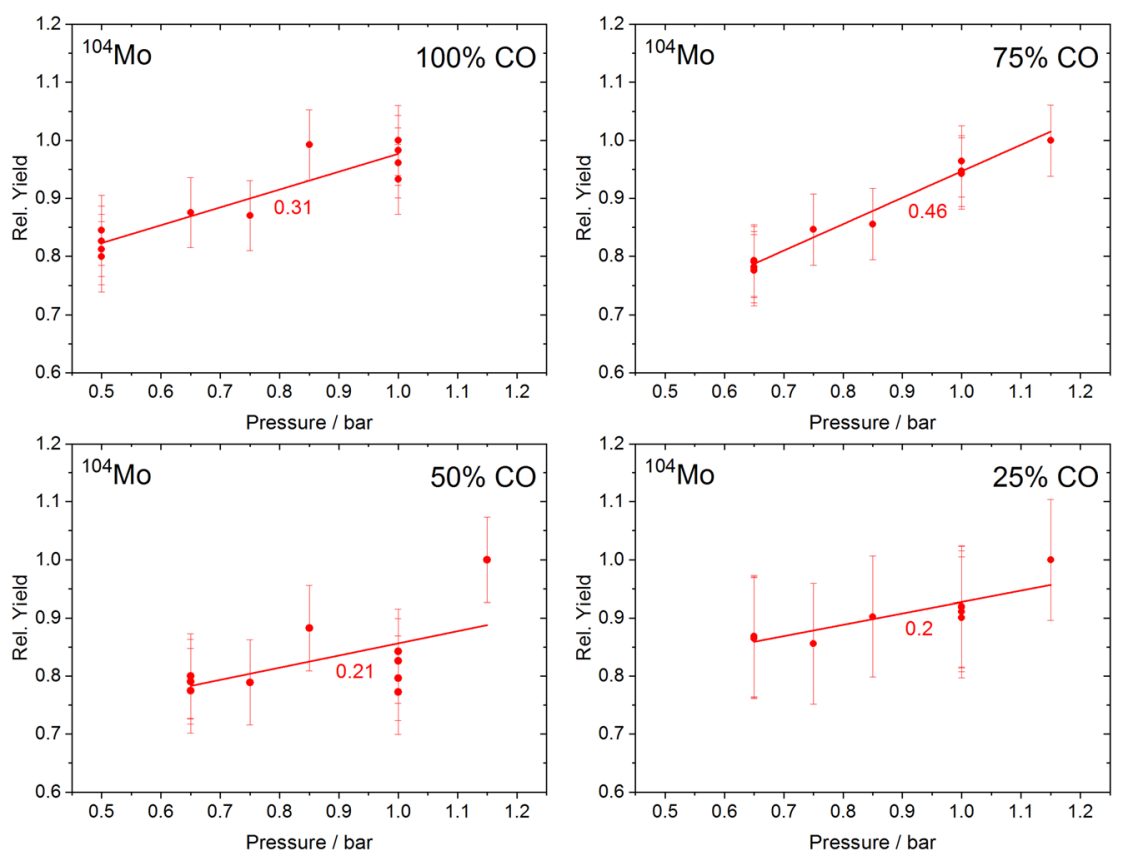

Figure 13: Pressure dependence of the overall yield for Mo-MCCs (red symbols) in different gas-mixtures.

Linear fits (red lines) were applied to all data to compare the slopes given as red numbers. The data are normalized to the highest yields.
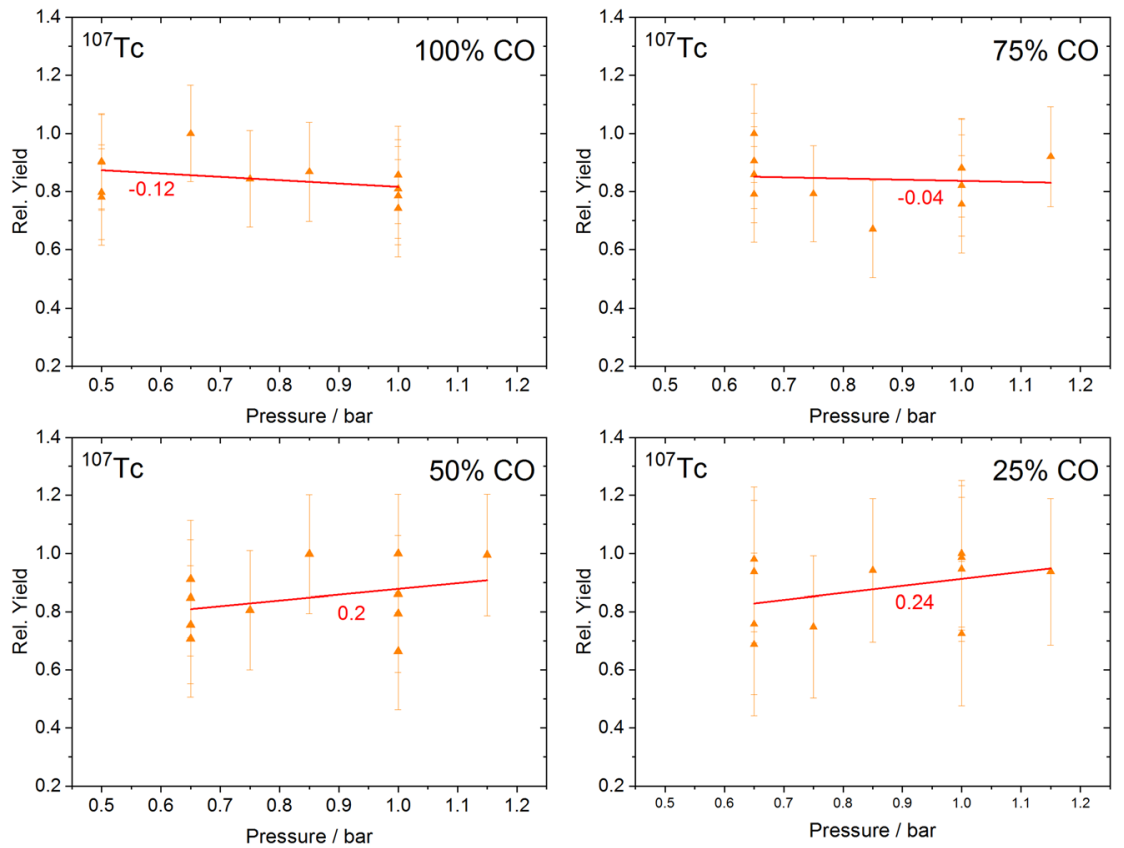

Figure 14: Pressure dependence of the overall yield for Tc-MCCs (orange symbols) in different gas-mixtures.

Linear fits (red lines) were applied to all data to compare the slopes given as red numbers. The data are normalized to the highest yields.

process gas. If yield-lowering effects are expected for Tc and $\mathrm{Ru}$ due to those two causes, they would have been expected to affect Rh even stronger.

\subsection{Kinetic energy}

It was investigated if the kinetic energy of fission products recoiling into the reaction chamber impacts the formation of MCCs. The results are shown in Figures 19-22.
Decreasing the range of fission products by increasing the thickness of the used degrader foil was found to decrease the overall yield for all investigated isotopes by up to $80 \%$. A series of simulations was performed to obtain insight into the observed dependency between overall MCC-yield and the kinetic energy of fission products entering the reaction chamber.

Figure 23 shows the reaction chamber of FORA scaled to the shown coordinate system together with the results from the SRIM simulations as an overlay. The position of 

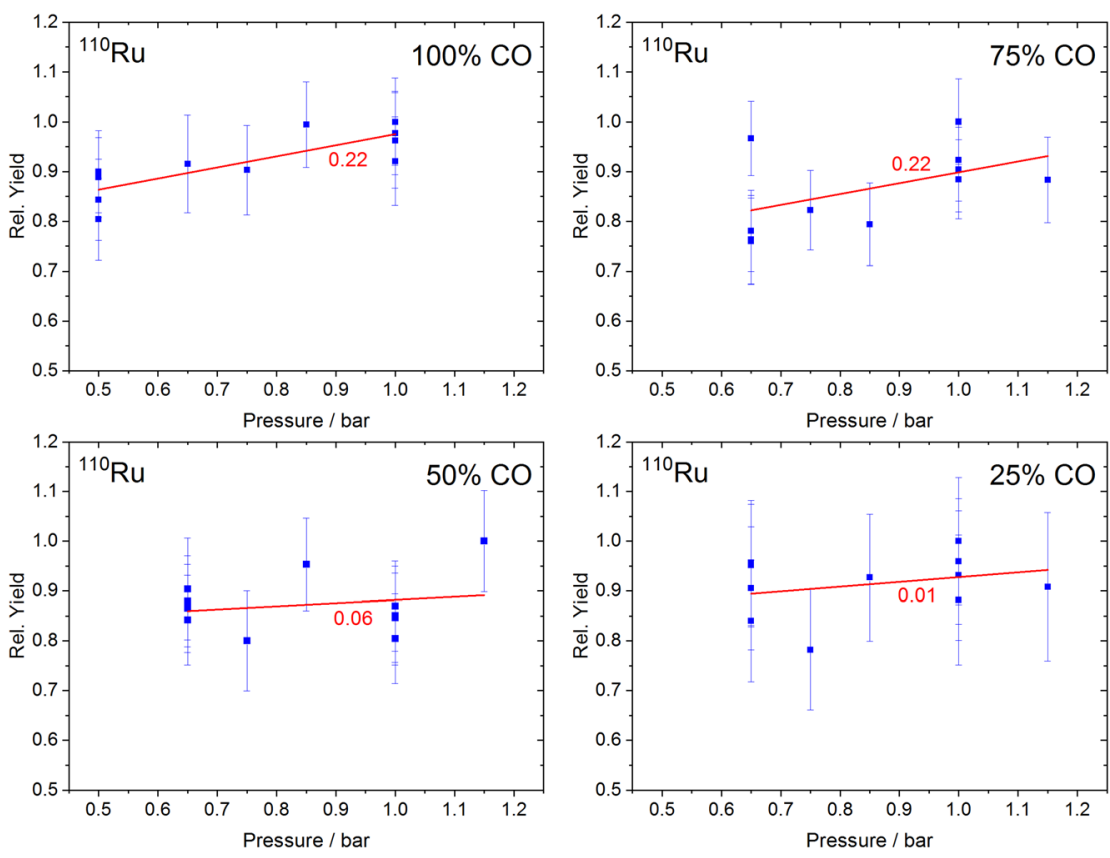

Figure 15: Pressure dependence of the overall yield for Ru-MCCs (blue symbols) in different gas-mixtures.

Linear fits (red lines) were applied to all data to compare the slopes given as red numbers. The data are normalized to the highest yields.
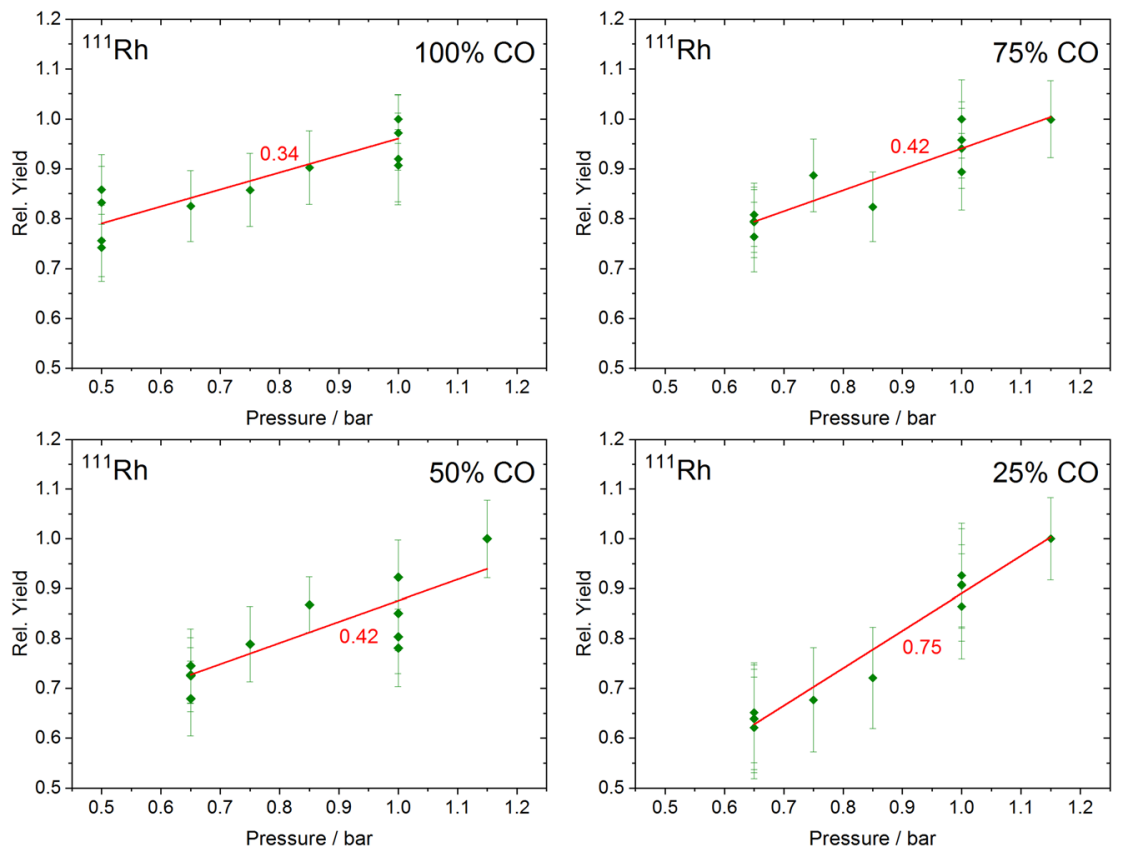

Figure 16: Pressure dependence of the overall yield for Rh-MCCs (green symbols) in different gas-mixtures.

Linear fits (red lines) were applied to all data to compare the slopes given as red numbers. The data are normalized to the highest yields.

the aluminum-wheel in which the degrader foils are mounted (cf. Figure 3) is indicated by the green horizontal line in Figure 23, $3 \mathrm{~mm}$ above the origin. In Figures 19-22 a decrease in overall yield upon reduction of fission product kinetic energy is observed. For $100 \% \mathrm{CO}$ as well as 50:50 gas mixtures of $\mathrm{CO}: \mathrm{N}_{2}$ and $\mathrm{CO}: \mathrm{Ar}$, this decrease is quantitatively comparable for all investigated isotopes and all mentioned process gases. Changing from operation without a degrader foil (maximum range) to a
$1.5 \mu \mathrm{m}$ thick foil (second highest range) causes a decrease in yield of roughly $50 \%$ while going from 1.5 to $3 \mu \mathrm{m}$ (smallest range) causes an additional decrease by about 20\%. Arguably, the decrease in 50:50 CO:Ar when going from 1.5 to $3 \mu \mathrm{m}$ is smaller than for 50:50 CO: $\mathrm{N}_{2}$ and 100\% CO. Considering the simulations shown in Figure 23, it is expected that 100\% CO and 50:50 CO: $\mathrm{N}_{2} /$ Ar show a very similar behavior towards kinetic energy variations, as the emission profiles of fission products in the three matrices 

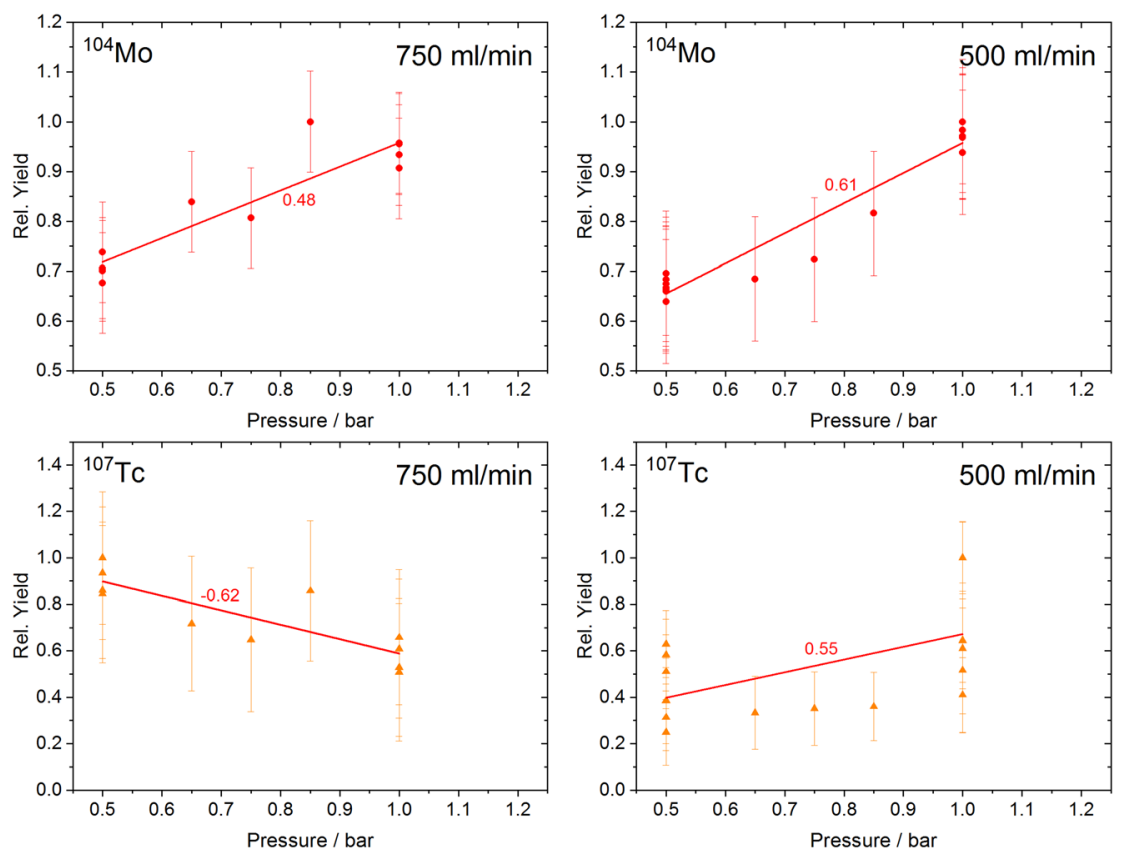

Figure 17: Pressure investigations for Mo (upper panels, red symbols) and Tc (lower panels, orange symbols) in $100 \%$ CO at two different gas flows. Linear fits (red lines) were applied to all data to compare the slopes given as red numbers.

The data are normalized to the highest yields.
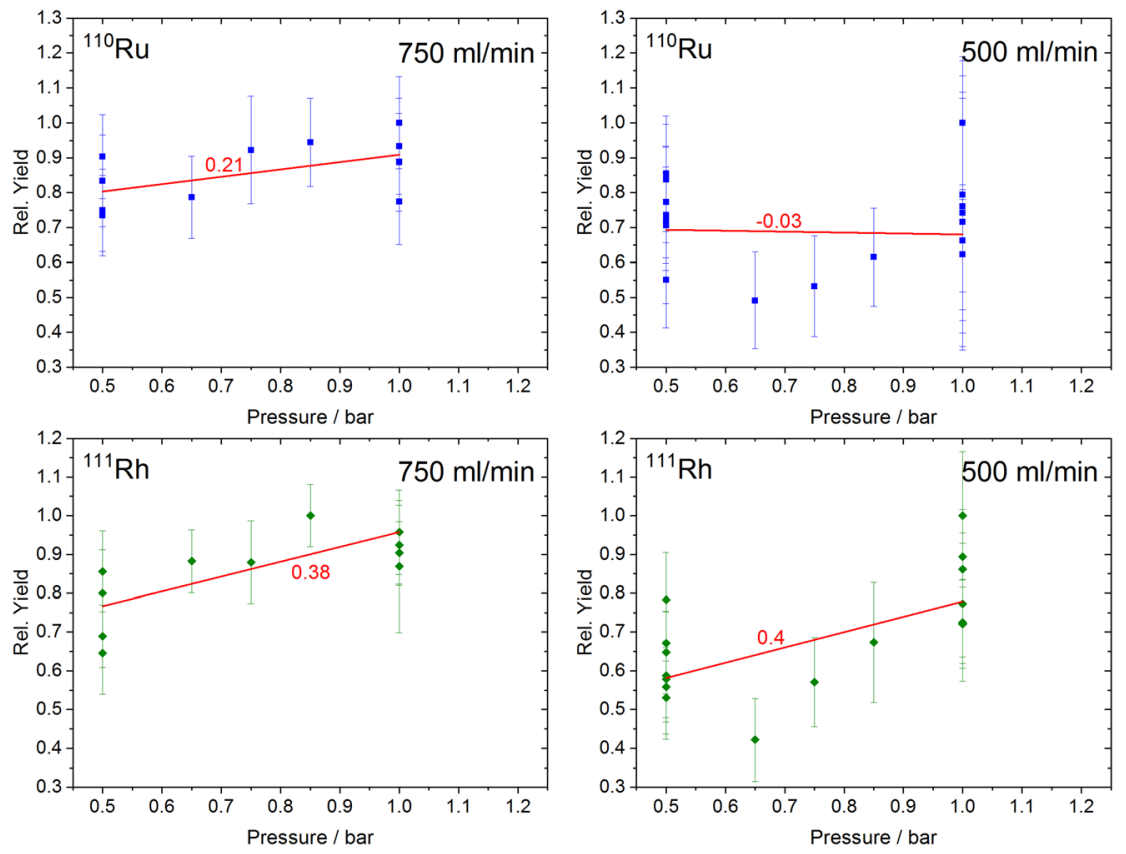

Figure 18: Pressure investigations for Ru (upper panels, blue symbols) and Rh (lower panels, green symbols) in $100 \%$ CO at two different gas flows.

Linear fits (red lines) were applied to all data to compare the slopes given as red numbers. The data are normalized to the highest yields.

are very similar. As this was also found experimentally, it illustrates that indeed, the observed behavior is caused by kinetic energy variations and not a potential interference, e.g., by impurities. There is a number of possible scenarios potentially explaining the observed decrease in yield. According to our simulations, fission products are stopped rather soon after entering the reaction chamber, between the two gas inlets at the side of the chamber. It could be argued that particles penetrating deeper into the reaction chamber are flushed out more efficiently, thereby resulting in shorter transport times. However, the fact that ${ }^{104} \mathrm{Mo}$ having a half-life of $60 \mathrm{~s}$ and ${ }^{111} \mathrm{Rh}$ with a half-life of only $11 \mathrm{~s}$ show the same behavior makes a simple transport based mechanism unlikely. As discussed in Section 3.1, reactions between partially decomposed MCCs and water adsorbed on PFA-TEFLON ${ }^{\circledR}$ surfaces are expected. Depending on the overall gas dynamics and diffusion kinetics, it cannot be excluded at this point that fission 

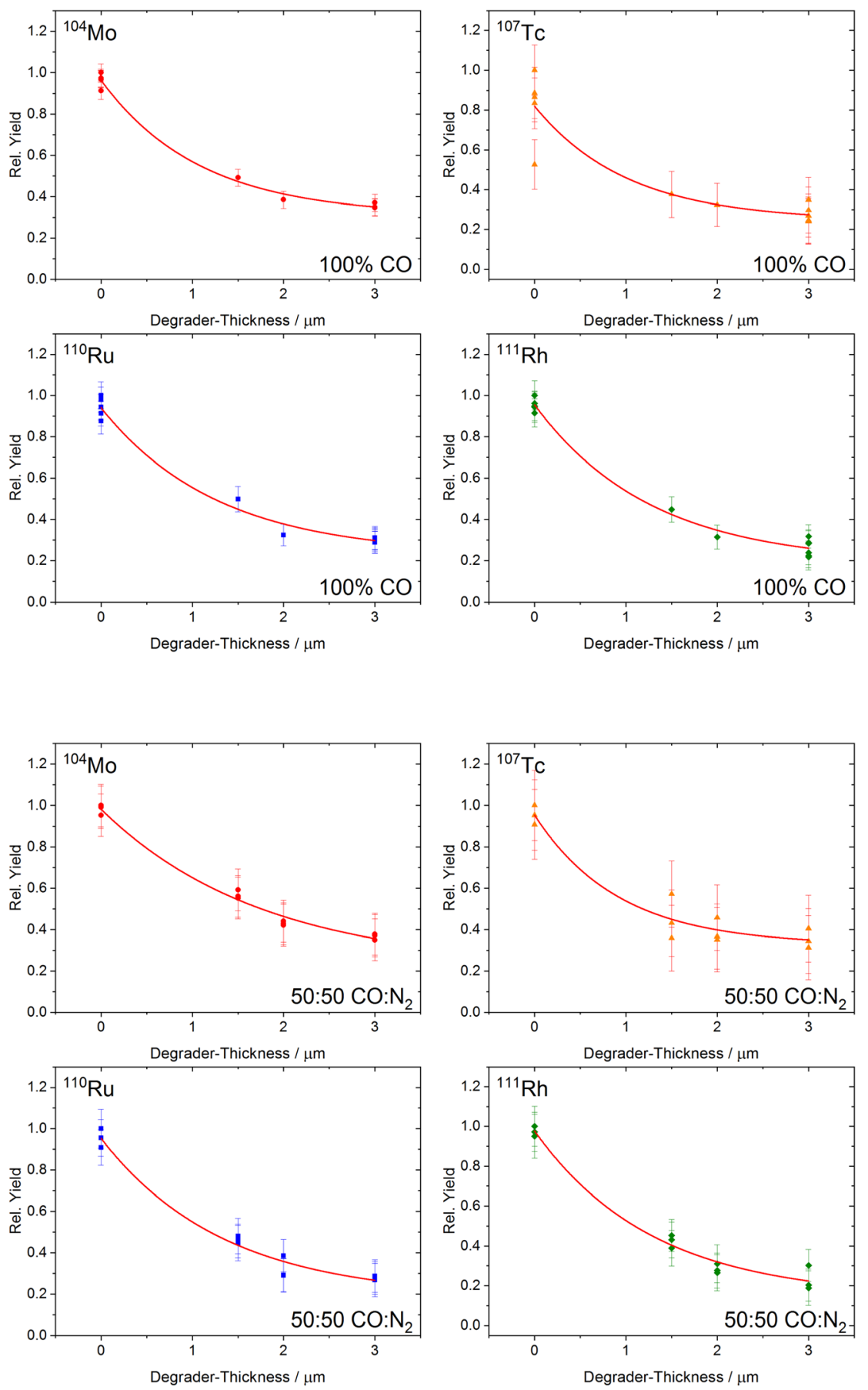

Figure 19: Effect of kinetic energy onto formation and transport of MCCs in $100 \%$ CO (colored symbols).

The thickness of the used degrader foil is depicted on the $x$-axis. A degrader thickness of $0 \mu \mathrm{m}$ corresponds to no degrader foil being used at all. Experimental details are given in the text. The signal is normalized to the highest obtained yield. The trend line (red line) is there to guide the eye.
Figure 20: Effect of kinetic energy onto formation and transport of MCCs in 50:50 $\mathrm{CO}: \mathrm{N}_{2}$ (colored symbols).

The thickness of the used degrader foil is depicted on the $x$-axis. A degrader thickness of $0 \mu \mathrm{m}$ corresponds to no degrader foil being used at all. Experimental details are given in the text. The signal is normalized to the highest obtained yield. The trend line (red line) is there to guide the eye. products being stopped earlier have a higher chance to come into contact with PFA-TEFLON® surfaces and therefore with adsorbed water molecules.

An alternative explanation for the observed behavior might be associated with atoms being able to enter the reaction chamber as a function of the applied degrader foil. One can assume that only fission products entering the larger volume of the reaction chamber are transported to the charcoal trap. A critical particle range to enter this volume could be arbitrarily defined in $y$-direction (along the $y$-axis in Figure 23). A particle not surpassing this range, is then assumed to not be transported, despite maybe still forming a MCC. By checking how many particles are, according to this definition, not entering the chamber and assuming all such particles to be lost in respect to the overall yield, one can predict overall yields as shown in Figure 24 and compare the outcome with the actual experiment. Figure 24 shows two sets of simulations 

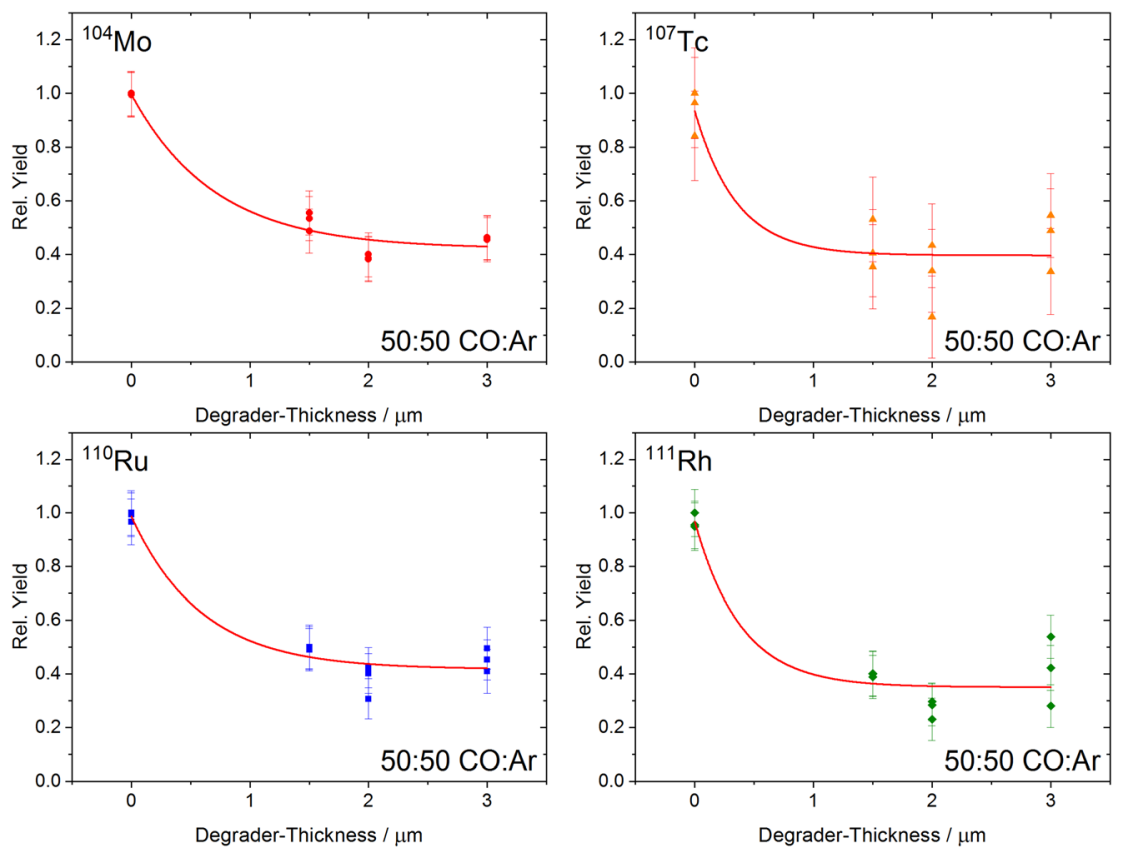

Figure 21: Effect of kinetic energy onto formation and transport of MCCs in 50:50 $\mathrm{CO}:$ Ar (colored symbols).

The thickness of the used degrader foil is depicted on the $x$-axis. A degrader thickness of $0 \mu \mathrm{m}$ corresponds to no degrader foil being used at all. Experimental details are given in the text. The signal is normalized to the highest obtained yield. The trend line (red line) is there to guide the eye.
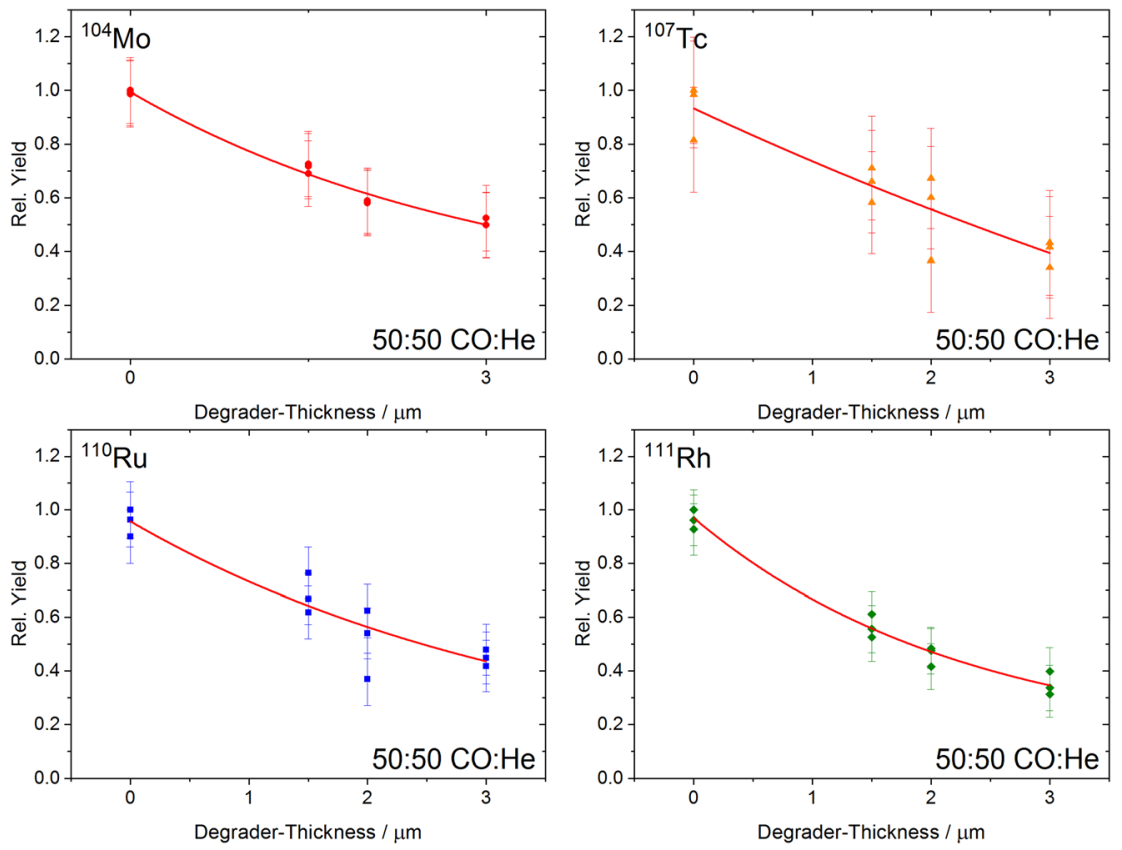

Figure 22: Effect of kinetic energy onto formation and transport of MCCs in 50:50 $\mathrm{CO}: \mathrm{He}$ (colored symbols).

The thickness of the used degrader foil is depicted on the $x$-axis. A degrader thickness of $0 \mu \mathrm{m}$ corresponds to no degrader foil being used at all. Experimental details are given in the text. The signal is normalized to the highest obtained yield. The trend line (red line) is there to guide the eye.

assuming fission products to require different critical ranges to be available for reaction and transport. The limit of $5.5 \mathrm{~mm}$ is the minimal distance fission products need to travel in order to reach the very bottom of the reaction chamber according to the geometry of the FORA-setup. The limit of $13.9 \mathrm{~mm}$ results from a least square error minimization procedure to find the critical range resulting in the best fit between simulations and experimental data, still not describing the observation. Note that such simulations must be handled with caution. Wittwer et al. [44] compared experimentally determined stopping ranges of atoms recoiling into gases with the ones determined by SRIM and found a discrepancy between the two values. The correction factor obtained in their work was deduced from elements much heavier than the ones investigated in this study. Since this correction factor is used in the simulations depicted in Figure 23, it is possible that actual ranges of fission products are overestimated or underestimated by $20-50 \%$. However, the comparison between the experimental data and results of the simulations shown in 

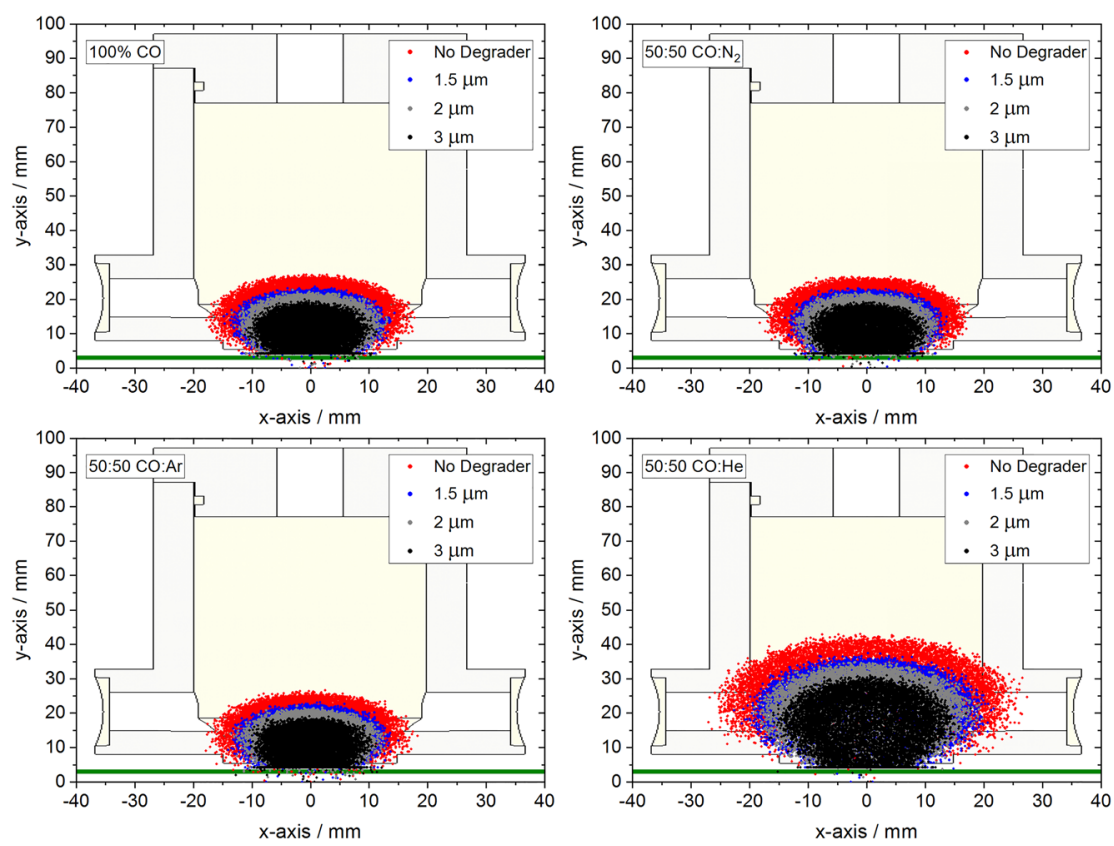

Figure 23: 2D-representation of the SRIM simulations depicting the position of fission products after thermalization in various process gases with various degrader foils.

An overlay of the results obtained from the SRIM simulations and the reaction chamber of the FORA-setup is depicted. The green horizontal line indicates the position of the aluminum-wheel with the incorporated degrader foil. Details concerning the simulations are given in the supporting information.

Figure 24 reveals that the stopping of fission products prior to entering the reaction chamber impacts the overall yield, but is not the only cause of the observed trend. Another loss

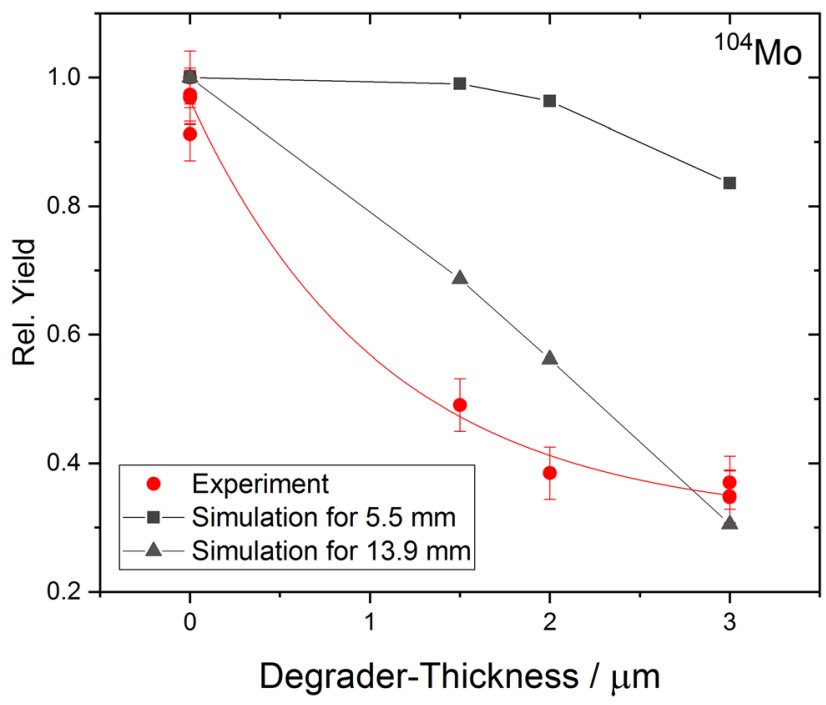

Figure 24: Influence of the degrader thickness on the yields for ${ }^{104} \mathrm{Mo}(\mathrm{CO})_{6}$ as shown in Figure 19 (red dots).

The black squares correspond to simulations assuming that fission products have to recoil at least $5.5 \mathrm{~mm}$ away from the ${ }^{252} \mathrm{Cf}$-source to form MCCs and to be thus transported to the detection setup. The black triangles correspond to the same, but assuming a minimal distance of $13.9 \mathrm{~mm}$ instead. These yields are calculated using the data shown in Figure 23. These data include the implantation loss of ions into the chamber walls. All data sets were normalized to the yield measured for the maximum ion range, i.e., without degrader. The lines are shown to guide the eye. factor is related to implantation of fission products into the chamber walls prior to thermalization. The data shown in Figure 23 include the implantation loss of ions into the chamber walls. This loss appears significant in the $\mathrm{CO} / \mathrm{He}$ mixture and not in the other gas mixtures. Severe implantation losses are not expected in 100\% CO and 50:50 $\mathrm{CO}: \mathrm{N}_{2} / \mathrm{Ar}$, else an opposite trend would have then be observed experimentally. However, it is worth pointing at the observed trend in 50:50 CO:He (Figure 22). It appears again that overall yields are decreasing with decreasing kinetic energies, but the yield loss determined between no degrader and a $1.5 \mu \mathrm{m}$ thick degrader foil amounts to only about $30 \%$, being significantly lower than for the other systems (cf. Figures 19-21). Figure 23 illustrates the much higher ranges of fission products in 50:50 CO:He in comparison to the other gas mixtures used, due to the small stopping power of He. The lower difference in relative yields observed in 50:50 CO:He is assumed to be caused by an already reduced yield without degrader foil due to implantation losses. This is in agreement with the measured data comparing the yield in different gas mixtures with Miss Piggy (see Figure 27).

\subsection{Temperature}

The effect of heating the reaction chamber of FORA was investigated.

Figures 25 and 26 depict the results obtained when varying the temperature of the reaction chamber. To elucidate the observed behavior, the data are not plotted 

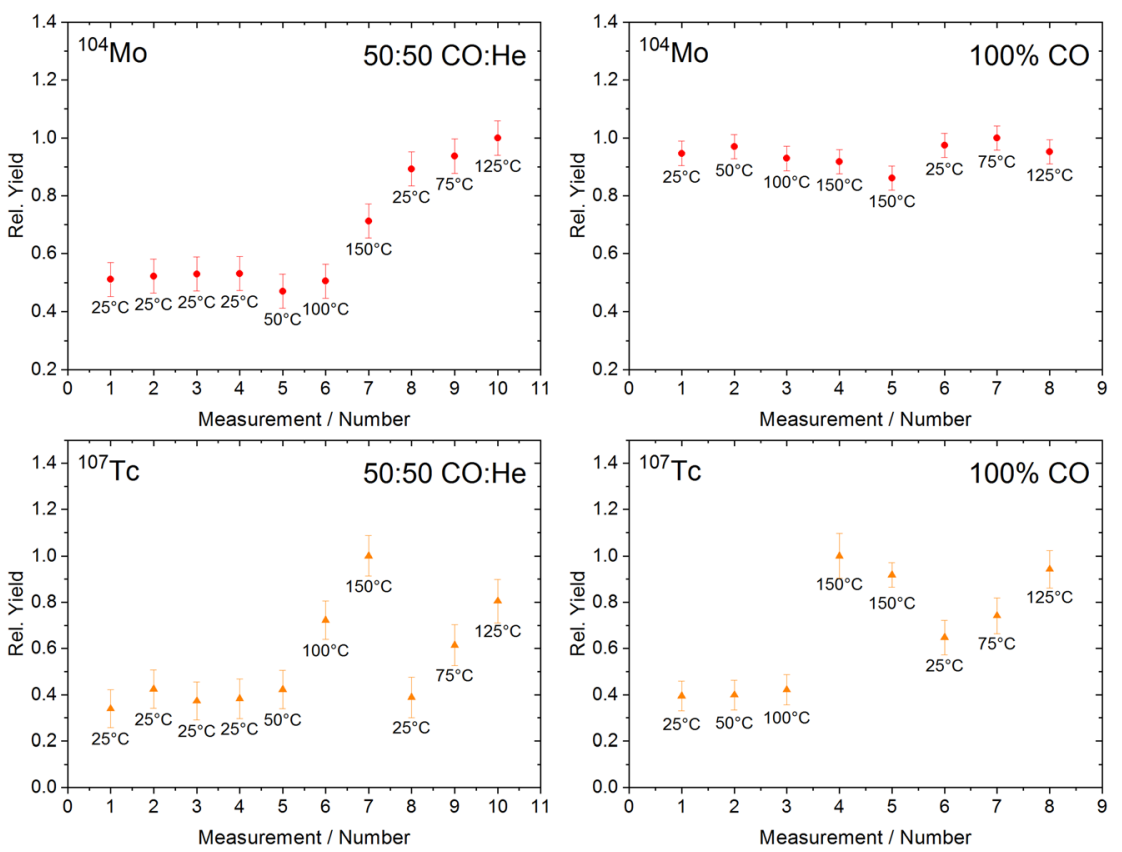

Figure 25: Effect of temperature onto the formation and transport of MCCs from Mo (upper panels) and Tc (lower panels). 50:50 CO:He (left) and 100\% CO (right) at $1.00 \mathrm{bar}$ and $1000 \mathrm{ml} / \mathrm{min}$ were used. The data are normalized to the highest measured yield. The temperature of the copper-oven is indicated below each measurement point.
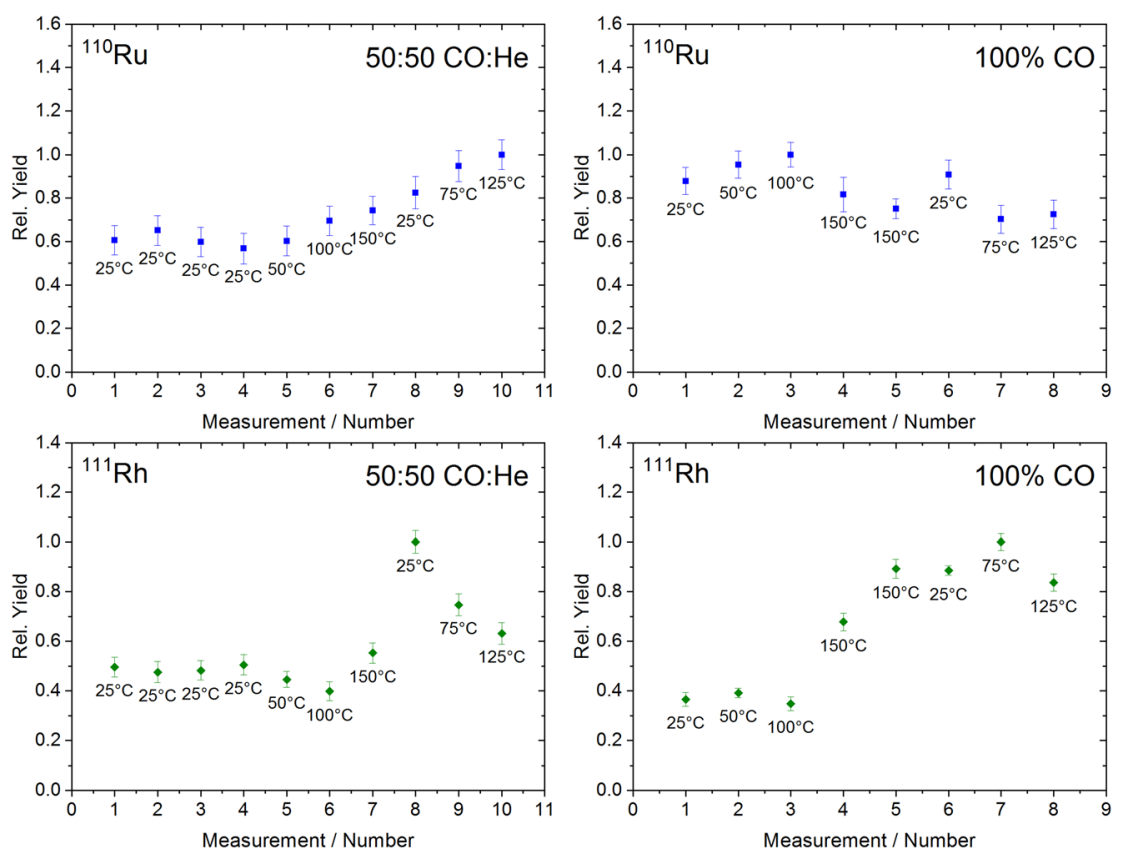

Figure 26: Effect of temperature onto the formation and transport of MCCs from Ru (upper panels) and Rh (lower panels). 50:50 CO:He (left) and 100\% CO (right) at $1.00 \mathrm{bar}$ and $1000 \mathrm{ml} / \mathrm{min}$ were used. The data are normalized to the highest measured yield. The temperature of the copper-oven is indicated below each measurement point.

against the temperature but against chronologically increasing measurement number. The temperature of the reaction chamber at each point of measurement is depicted below the data points. It was found that increasing the temperature of the reaction chamber increases the yield for formation/transport of volatile compounds. An increase in yield was observed for Tc and Rh in 100\% CO as well as in 50:50 CO:He. For Mo and Ru, the increase in yield was only pronounced in 50:50 CO:He. However, interestingly the yield does not decrease again after the subsequent reduction of the temperature. If a yield increase was caused by the temperature primarily, e.g., due to activation energy, by the selective decomposition of non-volatile side products or more frequent gas-phase interactions of the atoms and incomplete MCC molecules with CO due to Boltzmann statistics, one would expect the yield to decrease again if the system is cooled back to room temperature. This was only observed for Tc. For all other elements, the yield remained higher after cooling the system back down to room temperature. The non-reversibility 

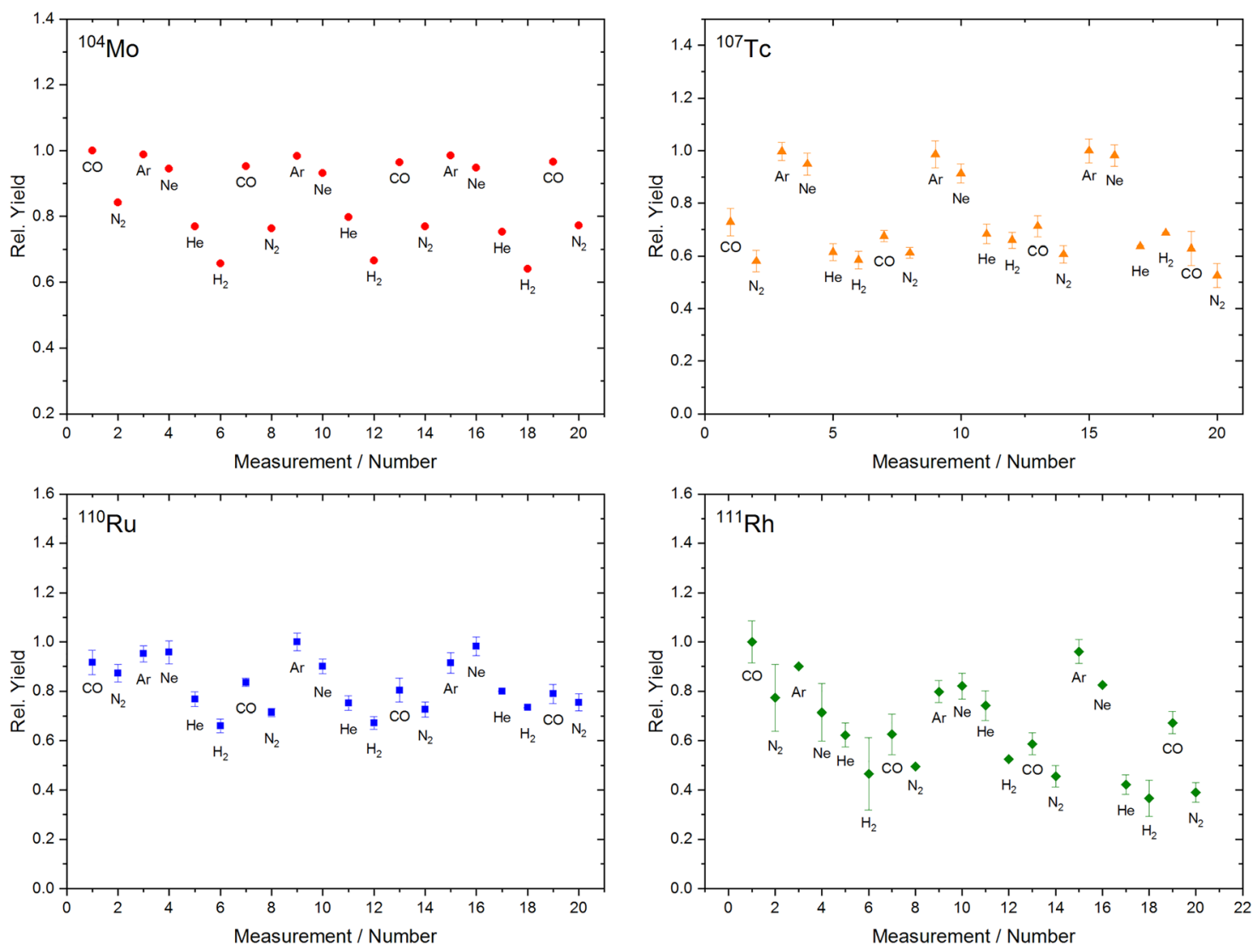

Figure 27: Investigations concerning the influence of different gas mixtures onto the overall yield for MCCs as measured with Miss Piggy. Each measurement was repeated multiple times to ensure reproducibility. 50:50 gas mixtures were used. Half of the process gas was always CO. The remaining $50 \%$ of the process gas was varied. The varied gases are indicated by the description below each measurement point. The pressure was set to 1.2 bar and the total gas flow to $600 \mathrm{sml} / \mathrm{min}$. The uncertainties correspond to the statistical error of the measurement.

associated with heating of the reaction chamber suggests a permanent change being caused by the increased temperature to the process gas or/and the FORA-system itself. As briefly discussed in the experimental section, it was found that the obtained yields in FORA are not constant but changing over time. This was assigned to $\mathrm{H}_{2} \mathrm{O}$ being slowly desorbed from the inner surfaces of the FORA-loop and subsequently adsorbed by the Sicapent ${ }^{\mathrm{TM}}$ column. Indeed, it was recently found that $\mathrm{H}_{2} \mathrm{O}$ has a strong effect onto the formation of inactive MCCs from Mo and Ru. For Tc, an increase in yield was observed upon adding larger amounts of water and for $\mathrm{Rh}$, the data were unfortunately not allowing for a clear conclusion about the dependence of its yield on the gas phase humidity [32]. It is suggested that the effects of temperature can be explained by desorption of water from the surfaces of the reaction chamber upon heating. If the chamber is heated, desorption of water is enhanced. It is subsequently transported along the setup and either depositing somewhere else or being adsorbed by a purification column. Since FORA is a closed, continuously operating gas-loop with a Sicapent ${ }^{\mathrm{TM}}$ column in front of the reaction chamber, desorption of water causes a permanent change to the reaction conditions slowly lowering the water content in the gas-phase and on the surfaces of the reaction chamber leading to the observed irreversibility of the heating effect. A waterinduced loss during adsorption of MCCs on the surface being responsible for the observed dependency on gas flow was discussed in Section 3.1. This explanation fits the behavior of $\mathrm{Mo}$ and $\mathrm{Ru}$. It corresponds to their sensitivity towards $\mathrm{H}_{2} \mathrm{O}$. In $100 \%$ CO, the effect was not visible. It is however expected that impurity effects become more severe at lower partial pressures of $\mathrm{CO}$, where the formation time of the MCCs shall be increased leaving a larger part of the incomplete MCCs to the competing water. For Rh, the effect is in principle observed as well. The yield appears to decrease again after a few hours in 50:50 CO:He which might be caused by a small re-accumulation of impurities. Indeed, Rh was suggested to be most sensitive towards impurities among the investigated elements, particularly towards $\mathrm{H}_{2} \mathrm{O}$ and $\mathrm{O}_{2}$ [32]. Tc is different as the yield for its MCC was decreasing to a much larger extend after cooling 
down the reaction chamber again. This is actually closer to the behavior expected from a direct effect of temperature. There is a number of possible explanation concerning the observations for Tc. As it was observed in [32] that larger amounts of $\mathrm{H}_{2} \mathrm{O}$ appear to increase the yield for volatile Tccompounds. The desorption of water might increases the observed Tc-yield due to an increase of moisture in the gasphase. This would be a reversible effect upon cooling the reaction chamber. Alternatively, it is also possible that an increased gas flow (compare with Equation (1)) is partially responsible for the observed behavior. By comparison with Figures 6, 8, and 9, the expected increase in yield from gas flow only upon heating the system from 25 to $150{ }^{\circ} \mathrm{C}$, assuming homogeneous heating of the process gas between reaction chamber and charcoal trap, amounts to a maximum of $20 \%$. However, gas flow based effects would influence the other MCC yields too, particularly ${ }^{104} \mathrm{Mo}$ (cf. Figures 8 and 9).

\subsection{Gas-mixtures}

The dependency of the overall MCC-yield on the used gas mixture using the Miss Piggy setup is depicted in Figure 27.

For Mo and $\mathrm{Ru}$, it was found that $100 \% \mathrm{CO}, 50: 50 \mathrm{CO}: \mathrm{Ar}$ and 50:50 CO:Ne give the highest yields. For Tc, the yields in 50:50 CO:Ar and 50:50 CO:Ne were found to be the highest. In recent studies using the Miss Piggy setup [32], it was not possible to obtain an analyzable signal for ${ }^{111} \mathrm{Rh}(\mathrm{CO})_{m}$, probably due to its short half-life and high sensitivity towards impurities since, contrary to FORA, Miss Piggy does not use any gs purification setups. To counteract this issue, the transport capillaries for this experiment were shortened in comparison to previous studies in order to reduce transport times. The reduced transport times allowed for an quantitative investigation of ${ }^{111} \mathrm{Rh}(\mathrm{CO})_{m}$, but the determined uncertainties are still higher than for the other investigated elements, $\mathrm{Rh}(\mathrm{CO})_{m}$ being more chemically sensitive. However, the overall observation appears to be similar to the other elements, meaning that yield in CO:Ar and CO:Ne have a tendency being higher than for the other gas mixtures. Particularly, for Tc it was found that different gas mixtures have a strong impact on the overall yield for volatile compounds. It appears that gas mixtures of 50:50 CO:Ar and 50:50 CO:Ne can result in higher yields than $100 \% \mathrm{CO}$, which is not in agreement with previous investigations concluding that overall yields are generally higher if higher $\mathrm{CO}$ contents in the process gas are used [34, 40-42, 45, 46]. As discussed in Section 3.3, implantation of fission products is expected to lower overall yields if gas mixtures with reduced stopping power are used. For 50:50 CO:He, this was found to be a dominant process at high kinetic energies. The reaction chamber in Miss Piggy is identical to the one used in FORA. Therefore, implantation in 50:50 CO:He (see Figure 23) will be equally severe. The same will be true in 50:50 CO: $\mathrm{H}_{2}$, explaining why those two gas mixtures gave the lowest overall yields for MCCs. $\mathrm{N}_{2}$ has similar stopping power for fission products as CO. Therefore, ranges in 100\% CO and 50:50 CO: $\mathrm{N}_{2}$ will be similar. The lower yields obtained for 50:50 CO: $\mathrm{N}_{2}$ in comparison with $100 \%$ CO can be clearly assigned to the higher $\mathrm{CO}$ content in the latter. The high yields for volatile compounds of Tc and less pronounced for Ru in 50:50 CO:Ar and 50:50 CO:Ne might be related to the kinetics of side reactions. Since Miss Piggy is not a gasloop and does not include purification columns, the used process gas contains larger amounts of impurities compared to FORA. In recent studies, the effect of Ar impurities in $\mathrm{CO}$ onto the overall yield for MCCs was investigated using FORA [32]. No effect was found up to $10 \mathrm{Vol}-\%$ of $\mathrm{Ar}$ in CO. According to the data presented here, this means that at an Ar-concentration $>10 \mathrm{Vol}-\%$, the MCC-yield should start to increase despite the increasing dilution of $\mathrm{CO}$. Further investigations will be necessary to confirm this. As implantation effects in 50:50 $\mathrm{CO}: \mathrm{H}_{2}$ and $\mathrm{CO}: \mathrm{He}$ are assumed to be the major source of losses, investigations of MCC-yields in those gas mixtures using reaction chambers with different geometries might be worth performing. It is possible, that those gas mixtures will show a significantly better performance if a differently sized chamber is used.

\section{Conclusion}

The data suggest a wide variety of reaction parameters being available for optimizing the yield for formation and transport of MCCs. Experiments requiring high yields for MCCs under single-atom chemistry conditions are suggested by this work to be performed at the highest pressure and gas flow values experimentally possible. As the effect of gas flow appears to be more significant than the one of pressure, maximizing the gas flow should be of higher priority. For group 6 elements, it is furthermore suggested to perform experiments in gas-mixtures containing large percentages of CO, optimally 100\%. 50:50 CO:Ar and 50:50 $\mathrm{CO}: \mathrm{Ne}$ are promising candidates as well, due to impurity dilution, stopping range and gas phase diffusion effects. For the elements of group 7 and 8 these mixtures seem to provide an alternative superior to pure $\mathrm{CO}$. In acceleratorbased setups including separators, the kinetic energy is a parameter that can be adjusted to some extent by using 
vacuum windows of various thicknesses. Stopping at longer range, away from the entrance window and from the walls of the recoil chamber, seems beneficial preventing surface adorption losses prior to the gas phase complex formation. Lastly, heating of the reaction chamber and transport capillaries up to $150^{\circ} \mathrm{C}$ was observed to increase MCC-yields. Particularly, a permanent or repeated heating of loop surfaces for removal of adsorbed water prior (for thermally unstable MCCs) and during the experiments (for thermally stable MCCs) has the potential to be of great benefit.

Author contributions: All the authors have accepted responsibility for the entire content of this submitted manuscript and approved submission.

Research funding: This work was supported by the Swiss National Science Foundation (grant 200021_162769).

Conflict of interest statement: The authors declare no conflicts of interest regarding this article.

\section{References}

1. Mond L., Langer C., Quincke F. Action of carbon monoxide on nickel. J. Chem. Soc. Trans. 1890, 57, 749-753.

2. Bhatt V. Essentials of coordination chemistry. In Chapter 8 Metal Carbonyls, 1st ed.; Elsevier: Amsterdam, 2015; pp. 191-236.

3. Söderberg B. C. G. Synthesis using transition metal carbonyl complexes. In Encyclopedia of Inorganic and Bioinorganic Chemistry. John Wiley \& sons: Weinheim, 2011 (online); https:// doi.org/10.1002/9781119951438.eibc0155.

4. Wareham L. K., Poole R. K., Tinajero-Trejo M. CO-releasing metal carbonyl compounds as antimicrobial agents in the postantibiotic era. J. Biol. Chem. 2015, 290, 18999-19007.

5. Johnson T. R., Mann B. E., Clark J. E., Foresti R., Green C. J., Motterlini R. Metal carbonyls: a new class of pharmaceuticals? Angew. Chem. Int. Ed. 2003, 42, 3722-3729.

6. Schatzschneider U. Novel lead structures and activation mechanisms for CO-releasing molecules (CORMs). $\mathrm{Br}$. J. Pharmacol. 2015, 172, 1638-1650.

7. Miroslavov A. E., Gorshkov N. I., Lumpov A. L., Yalfimov A. N., Suglobov D. N., Ellis B. L., Braddock R., Smith A. M., Prescott M. C., Lawson R. S., Sharma H. L. Evaluation of ${ }^{99 m} \mathrm{Tc}(\mathrm{CO})_{5} \mathrm{l}$ as a potential lung perfusion agent. Nucl. Med. Biol. 2009, 36, 73-79.

8. Türler A., Pershina V. Advances in the production and chemistry of the heaviest elements. Chem. Rev. 2013, 113, 1237-1312.

9. Schädel M. Chemistry of the superheavy elements. Phil. Trans. Roy. Soc. A 2015, 373, 1-15.

10. Schädel M. Chemistry of superheavy elements. Angew. Chem. Int. Ed. 2006, 45, 368-401.

11. Pershina V. Chapter 1: the chemistry of the super heavy elements and relativistic effects. In Theoretical and Computational Chemistry, 14th ed.; Elsevier B. V.: Amsterdam, 2004; pp. 1-80.

12. Pyykkö P. Relativistic quantum chemistry. Adv. Quant. Chem. 1978, 11, 353-409.
13. Eichler R. First foot prints of chemistry on the shore of the island of superheavy elements. J. Phys. Conf. 2013, 420, 1-17.

14. Loveland W. Superheavy carbonyls. Science 2014, 345, 1451-1452.

15. Türler A., Buklanov G. V., Eichler B., Gäggeler H. W., Grantz M., Hübener S., Jost D. T., Lebedev V. Y., Piguet D., Timokhin S. N., Yakushev A. B., Zvara I. Evidence for relativistic effects in the chemistry of element 104. J. Alloys Compd. 1998, 271-273, 287-291.

16. Sylwester E. R., Gregorich K. E., Lee D. M., Kadkhodayan B., Türler A., Adams J. L., Kacher C. D., Lane M. R., Laue C. A., McGrath C. A., Shaughnessy D. A., Strellis D. A., Wilk P. A., Hoffman D. C. On-line gas chromatographic studies of Rf, $\mathrm{Zr}$, and $\mathrm{Hf}$ bromides. Radiochim. Acta 2000, 88, 837-843.

17. Kadkhodayan B., Türler A., Gregorich K. E., Baisden P. A., Czerwinski K. R., Eichler B., Gäggeler H. W., Hamilton T. M., Jost D. T., Kacher C. D., Kovacs A., Kreek S. A., Lane M. R., Mohar M. F., Neu M. P., Stoyer N. J., Sylwester E. R., Lee D. M., Nurmia M. J., Seaborg G. T., Hoffman D. C. On-line gas chromatographic studies of chlorides of rutherfordium and homologs $\mathrm{Zr}$ and $\mathrm{Hf}$. Radiochim. Acta 1996, 72, 169-178.

18. Gäggeler H. W., Jost D. T., Kovacs J., Scherer U. W., Weber A., Vermeulen D., Türler A., Gregorich K. E., Henderson R. A., Czerwinski K. R., Kadkhodayan B., Lee D. M., Nurmia M., Hoffman D. C., Kratz J. V., Gober M. K., Zimmermann H. P., Schädel M., Brüchle W., Schimpf E., Zvara I. Gas phase chromatography experiments with bromides of tantalum and element 105. Radiochim. Acta 1992, 57, 93-100.

19. Türler A., Eichler B., Jost D. T., Piguet D., Gäggeler H. W., Gregorich K. E., Kadkhodayan B., Kreek S. A., Lee D. M., Mohar M., Sylwester E., Hoffman D. C., Hübener S. On-line gas phase chromatography with chlorides of niobium and hahnium (element 105). Radiochim. Acta 1996, 73, 55-66.

20. Qin Z., Lin M. S., Fan F. L., Huang W. X., Yan X. L., Bai J., Wu X. L., Lei F. A., Ding H. J., Ma F., Li G. S., Zhou H. B., Guo J. S. On-line gas chromatographic studies of Nb, Ta, and $\mathrm{Db}$ bromides. Radiochim. Acta 2012, 100, 285-289.

21. Schädel M., Brüchle W., Dressler R., Eichler B., Gäggeler H. W., Günther R., Gregorich K. E., Hoffman D. C., Hübener S., Jost D. T., Kratz J. V., Paulus W., Schumann D., Timokhin S., Trautmann N., Türler A., Wirth G., Yakuschev A. Chemical properties of element 106 (seaborgium). Nature 1997, 388, 55-57.

22. Türler A., Brüchle W., Dressler R., Eichler B., Eichler R., Gäggeler H. W., Gärtner M., Glatz J. P., Gregorich K. E., Hübener S. , Jost D. T., Lebedev V. Y., Pershina V. G., Schädel M., Taut S., Timokhin S. N., Trautmann N., Vahle A., Yakushev A. B. First measurement of a thermochemical property of a seaborgium compound. Angew. Chem. Int. Ed. 1999, 38, 2212-2213; https:// doi.org/10.1002/(sici)1521-3773(19990802)38:15<2212::aidanie2212>3.0.co;2-6.

23. Eichler R., Brüchle W., Dressler R., Düllmann C. E., Eichler B., Gäggeler H. W., Gregorich K. E., Hoffman D. C., Hübener S., Jost D. T., Kirbach U. W., Laue C. A., Lavanchy V. M., Nitsche H., Patin J. B., Piguet D., Schädel M., Shaughnessy D. A., Strellis D. A., Taut S., Tobler L., Tsyganov Y. S., Türler A., Vahle A., Wilk P. A., Yakushev A. B. Chemical characterization of bohrium (element 107). Nature 2000, 407, 63-65.

24. Hübener S., Taut S., Vahle A., Dressler R., Eichler B., Gäggeler H. W., Jost D. T., Piguet D., Türler A., Brüchle W., Jäger E., Schädel M., Schimpf E., Kirbach U., Trautmann N., Yakushev A. B. Physico- 
chemical characterization of seaborgium as oxide hydroxide. Radiochim. Acta 2001, 89, 737-741.

25. Düllmann C. E., Brüchle W., Dressler R., Eberhardt K., Eichler B., Eichler R., Gäggeler H. W., Ginter T. N., Glaus F., Gregorich K. E., Hoffman D. C., Jäger E., Jost D. T., Kirbach U. W., Lee D. M., Nitsche H., Patin J. B., Pershina V., Piguet D., Qin Z., Schädel M., Schausten B., Schimpf E., Schött H. J., Soverna S., Sudowe R., Thörle P., Timokhin S. N., Trautmann N., Türler A., Vahle A., Wirth G., Yakushev A. B., Zielinski P. M. Chemical investigation of hassium (element 108). Nature 2002, 418, 859-862.

26. Türler A., Eichler R., Yakushev A. Chemical studies of elements with $Z \geq 104$ in gas phase. Nucl. Phys. 2015, 944, 640-689.

27. Eichler R., Asai M., Brand H., Chiera N. M., Nitto A. D., Dressler R., Düllmann C. E., Even J., Fangli F., Goetz M., Haba H., Hartmann W., Jäger E., Kaji D., Kanaya J., Kaneya Y., Khuyagbaatar J., Kindler B., Komori Y., Kraus B., Kratz J. V., Krier J., Kudou Y., Kurz N., Miyashita S., Morimoto K., Morita K., Murakami M., Nagame Y., Ooe K., Piguet D., Sato N., Sato T. K., Steiner J., Steinegger P., Sumita T., Takeyama M., Tanaka K., Tomitsuka T., Toyoshima A., Tsukada K., Türler A., Usoltsev I., Wakabayashi Y., Wang Y., Wiehl N., Wittwer Y., Yakushev A., Yamaki S., Yano S., Yamaki S., Qin Z. Complex chemistry with complex compounds. EPJ Web Conf. 2016, 131, 1-7.

28. Even J., Yakushev A., Düllmann C. E., Haba H., Asai M., Sato T. K., Brand H., Nitto A. D., Eichler R., Fan F. L., Hartmann W., Huang M., Jäger E., Kaji D., Kanaya J., Kaneya Y., Khuyagbaatar J., Kindler B., Kratz J. V., Krier J., Kudou Y., Kurz N., Lommel B., Miyashita S., Morimoto K., Morita K., Murakami M., Nagame Y., Nitsche H., Ooe K., Qin Z., Schädel M., Steiner J., Sumita T., Takeyama M., Tanaka K., Toyoshima A., Tsukada K., Türler A., Usoltsev I., Wakabayashi Y., Wang Y., Wiehl N., Yamaki S. Synthesis and detection of a seaborgium carbonyl complex. Science 2014, 345, 1491-1493.

29. Ballof J., Seiffert C., Crepieux B., Ramos J. P., Rothe S., Stora T., Düllmann C. E.. Volatile Carbonyl Compounds for New Radioactive Ion Beams at ISOLDE; TASCA17 Conference Abstract: Germany, 2017.

30. Ballof J., Seiffert C., Stora T., Düllmann C. E., Yakushev A. Refractory beams at ISOLDE - a concept for a fission recoil target. In 6 Workshop on Nuclear Fission and Spectroscopy of Neutronrich Nuclei, Abstracts and Slides; ILL: Grenoble, France, 2017; p. 1429.

31. Düllmann C. E., Eichler B., Eichler R., Gäggeler H. W., Jost D. T., Kindler U., Piguet D., Soverna S., Thörle P., Trautmann N., Türler A. Miss Piggy, a californium-252 fission fragment source as a generator of short-lived radionuclides. Nucl. Instrum. Methods Phys. Res. 2003, 512, 595-605.

32. Wittwer Y., Eichler R., Herrmann D., Türler A. The influence of chemical parameters on the in-situ metal carbonyl complex formation studied with the fast on-line reaction apparatus (FORA). Radiochim. Acta 2021.

33. Wittwer Y., Eichler R., Zingg R., Herrmann D., Türler A. Investigations of the in-situ formation of metal-carbonylcomplexes using the FORA setup: gas purification and enhancement by macroscopic carbonyl addition. Radochim. Acta 2020, Submitted for publication.

34. Usoltsev I., Eichler R., Wang Y., Even J., Yakushev A., Haba H., Asai M., Brand H., Nitto A. D., Düllmann C. E., Fangli F., Hartmann W., Huang M., Jäger E., Kaji D., Kanaya J., Kaneya Y., Khuyagbaatar J., Kindler B., Kratz J. V., Krier J., Kudou Y., Kurz N., Lommel B.,
Miyashita S., Morimoto K., Morita K., Murakami M., Nagame Y., Nitsche H., Ooe K., Sato T. K., Schädel M., Steiner J., Steinegger P., Sumita T., Takeyama M., Tanaka K., Toyoshima A., Tsukada K., Türler A., Wakabayashi Y., Wiehl N., Yamaki S., Qin Z.

Decomposition studies of group 6 hexacarbonyl complexes. Part 1: production and decomposition of $\mathrm{Mo}(\mathrm{CO})_{6}$ and $\mathrm{W}(\mathrm{CO})_{6}$. Radiochim. Acta 2016, 104, 141-151.

35. Instruments $M$. Flow measurement $\&$ control frequently asked questions. www.mksinst.com (accessed Dec, 2019).

36. Jo D. H., Park C., Jung H., Kim S. H. Adsorption of carbon dioxide onto tetraethylenepentamine impregnated PMMA sorbents with different pore structure. Kor. Chem. Eng. Res. 2015, 53, 382-390.

37. Nucleonica. Database: ENDF/B-VIII.0 (accessed Feb, 2020).

38. Ziegler J. F., Ziegler M. D., Biersack J. P. SRIM - the stopping and range of ions in matter. Nucl. Instrum. Methods Phys. Res. B 2010, $268,1818-1823$.

39. Zvara I. Simulation of thermo chromatographic processes by the Monte Carlo method. Radiochim. Acta 1985, 38, 95-101.

40. Wang Y., Qin Z., Fan F. L., Fan F. Y., Cao S. W., Wu X. L., Zhang X., Bai J., Yin X. J., Tian L. L., Zhao L., Tian W., Li Z., Tan C. M., Guo J. S., Gäggeler H. W. Gas-phase chemistry of Mo, Ru, W and Os metal carbonyl complexes. Radiochim. Acta 2014, 102, 69-76.

41. Wang Y., Qin Z., Fan F. L., Haba H., Komori Y., Cao S. W., Wu X. L., Tan C. M. Gas-phase chemistry of technetium carbonyl complexes. Phys. Chem. Chem. Phys. 2015, 17, 13288-13234.

42. Cao S., Wang Y., Qin Z., Fan F., Haba H., Komori Y., Wu X., Tan C., Zhang X. Gas-phase chemistry of ruthenium and rhodium carbonyl complexes. Phys. Chem. Chem. Phys. 2016, 18, 119-125.

43. Schmitt H. W., Kiker W. E., Williams C. W. Precision measurements of correlated energies and velocities of ${ }^{252} \mathrm{Cf}$ fission fragments. Phys. Rev. 1965, 137, 837-847.

44. Wittwer D., Abdullin F. S., Aksenov N. V., Albin Y. V., Bozhikov G. A., Dmitriev S. N., Dressler R., Eichler R., Gäggeler H. W., Henderson R. A., Hübener S., Kenneally J. M., Lebedev V. Y., Lobanov Y. V., Moody K. J., Oganessian Y. T., Petrushkin O. V., Polyakov A. N., Piguet D., Rasmussen P., Sagaidak R. N., Serov A., Shirokovsky I. V., Shaughnessy D. A., Shishkin S. V., Sukhov A. M., Stoyer M. A., Stoyer N. J., Tereshatov E. E., Tsyganov Y. S., Utyonkov V. K., Vostokin G. K., Wegrzecki M., Wilk P. A. Gas phase chemical studies of superheavy elements using the dubna gasfilled recoil separator - stopping range determination. Nucl. Instrum. Methods Phys. Res. B 2010, 268, 28-35.

45. Even J., Yakushev A., Düllmann C. E., Dvorak J., Eichler R., Gothe O., Hild D., Jäger E., Khuyagbaatar J., Kratz J. V., Krier J., Niewisch L., Nitsche H., Pysmenetska I., Schädel M., Schausten B., Türler A., Wiehl N., Wittwer D. Rapid synthesis of radioactive transitionmetal carbonyl complexes at ambient conditions. Inorg. Chem. 2012, 51, 6431-6433.

46. Even J., Yakushev A., Düllmann C. E., Dvorak J., Eichler R., Gothe O., Hartmann W., Hild D., Jäger E., Khuyagbaatar J., Kindler B., Kratz J. V., Krier J., Lommel B., Niewisch L., Nitsche H., Pysmenetska I., Schädel M., Schausten B., Türler A., Wiehl N., Wittwer D. In-situ formation, thermal decomposition, and adsorption studies of transition metal carbonyl complexes with short-lived radioisotopes. Radiochim. Acta 2014, 102, 1093-1110.

Supplementary Material: The online version of this article offers supplementary material (https://doi.org/10.1515/ract-2020-0035). 